\title{
Proteomic Analysis of Wnt-Dependent Dishevelled-Based Supermolecular Complexes
}

\author{
Noriko Yokoyama \\ State University of New York at Stony Brook, Stony Brook, New York \\ USA
}

\section{Introduction}

Wnt signaling is critical and indispensable for numerous cellular pathways including embryonic development and adult tissue homeostasis such as determination, proliferation, migration and differentiation (Clevers, 2006; Glass and Karsenty, 2006; Nusse, 2005; Wang and Wynshaw-Boris, 2004). There are three independent branches of the Wnt signaling cascade, Wnt canonical beta-catenin/Lef-Tcf-sensitive transcriptional response, the planar

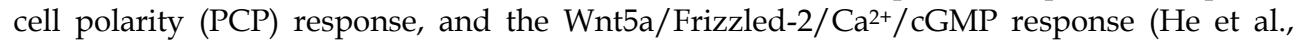
2004; Katanaev et al., 2005; Liu et al., 2001; Malbon, 2005; Wallingford and Habas, 2005; Willert et al., 2003). Dishevelleds (Dvls) are essential components in three major Wnt signaling pathways. Dvls function as scaffold protein bridging the receptors and distinct downstream signaling components. Through formation of dynamic multiprotein complexes, signal is transduced to inside cells.

In Wnt/beta-catenin signaling pathway, Wnts bind to members of the Frizzled (Fz) family of $G$ protein-coupled receptors and to co-receptor low density lipoprotein receptor related protein LRP5 and LRP6 (LRP5/6). Binding of Wnt3a to these receptors facilitates a variety of intracellular events. Phosphorylation of LRP5/6 triggers the interaction of Fz-LRP5/6 complex with dynamic multiprotein complexes, including adenomatous polyposis coli (APC),

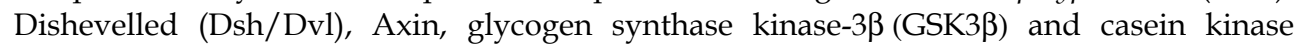
$1 \alpha$ (Hart, 1998; Kishida et al., 1998). Scaffold protein Dvl facilitates destruction of multiprotein complexes (Hart, 1998 ; Kishida et al., 1998; Malbon, 2005). As a results, stabilized $\beta$-catenin, translocates to nuclear and enhances Lef/Tcf-sensitive transcription (Angers \& Moon, 2009; Clevers, 2006; van Amerongen and Nusse, 2009).

Fly Dsh and three isoforms of mammals Dvls (Dvl1-3) all share several prominent, highlyconserved domains: a Dsh homology domain called DIX; a conserved sequence element with homology to the postsynaptic density protein PSD-95, Discs-large, and ZO-1, termed PDZ; and Disheveled, Egl-10, Pleckstrin domain, termed DEP (Wharton, 2003). In addition, there are conserved sequence regions harboring basic amino acids residues and a prolinerich putative Src homology 3 (SH3) binding domain (Penton et al., 2002). Dvl3 knockout mouse is lethal, whereas Dvl1 or Dvl2 knockout mouse is viable (Hamblet et al., 2002; Etheridge et al., 2008; Lijam et al., 1997). The isoforms of mammals Dvl are not truly "redundant" with respect to function (Hamblet et al., 2002; Etheridge et al., 2008; Lee et al., 2008), although functions of each isoform of Dvls are not fully resolved. Previous studies reveal distinct localization of Dvl isoforms in totipotent mouse F9 embryonal 
teratocarcinoma (F9) cells. Dvl1 and Dvl2 are found in the cytosol-enriched fraction (80 \%), the least amount of each of these isoforms is observed in the nuclear-enriched fraction (5\%). Dvl3 content in the cytosol-enriched fraction is reduced to $60 \%$, whereas content of Dvl3 in the nuclear-enriched fraction is several fold greater than that for either Dvl1 or Dvl2 (20\%). Abundance of Dvl3 and Dvl1 following Wnt3a stimulation is increased and Wnt3a stimulates dramatic Dvl3 trafficking to the plasma membrane. Thus, Dvl3 has a role in Wnt/ $\beta$-catenin signaling that is distinct from those of the Dvl1 and Dvl2 (Yokoyama et al., 2007). Dvl3 has unique roles in Wnt/ $\beta$-catenin signaling pathway (Lee et al., 2008; Yokoyama et al., 2007). Dvls are believed to be recruited Fz receptor through their PDZ domain. Many Dvls associating proteins also interact with Dvls via their PDZ domain (Wong et al., 2003). The DIX domain is critical for the ability of Dvl to recruit Axin and for the dynamic self-association of Dvls. Fluorescence microscopy in cells suggests that Dvls undergo dynamic oligomerization associated with activation of $\mathrm{Wnt} / \beta$-catenin signaling by Wnt3a (Axelrod et al., 1998; Kishida et al., 1999; Rothbacher et al., 2000). Properties of dynamic polymerization correlate with the activation of Wnt/ $\beta$-catenin signaling (SchwarzRomond et al., 2007a; Schwarz-Romond et al., 2007b). Wnt induces LRP6 aggregation and phosphorylation in a Dvl-dependent manner. Furthermore, Dvl mutants that lack normal oligomerization also influence the formation of LRP6 complexes (Bilic et al., 2007).

Thus, Dvls scaffold many interacting proteins temporally/spatially to transduce Wnt signaling. To define a regulation of Wnt signaling, it is necessary to establish the regulatory mechanism of assembly of Dvls-based supermolecular complexes. Tight regulation of Wnt signaling by protein-protein interaction involves many post-translational modifications such as phosphorylation, ubiquitination, sumoylation and methylation. Phosphorylation is a crucial and central mechanism of regulating docking of signal molecules to Dvl scaffold. Phosphorylation of protein regulates protein activities, binding affinities, stability and its trafficking to distinct cellular compartments (Yokoyama and Malbon, 2007; Yokoyama et al., 2007; Yokoyama and Malbon, 2009).

To probing Dvls-based complexes, two different approaches were employed. First, our attention is to identify interacting proteins of Dvl2 (most abundant form of Dvl in F9 cells). Dvl2 interacting proteins have been established using glutathione-S-transferase (GST) fusion protein pull down. Interacting proteins were pulled down and eluted from the beads. Eluted proteins were separated by immobilized $\mathrm{pH}$ gradient (IPG) strips ( $\mathrm{pH} 3-10$, first dimension separation) and subjected to second dimensional SDS-gel electrophoresis. Samples were analyzed by liquid chromatography electrospray ionization mass spectrometry (LC-ESI-MSMS). Novel Dvls interacting proteins were identified. In addition, immobilized Dvl2 domains pull down is able to find novel roles of Src in Wnt signaling. Identification of tyrosine phosphorylation sites on Dvl2 by Src family tyrosine kinases led to discover that Src family tyrosine kinases are a positive regulator of $\mathrm{Wnt} / \beta$-catenin signaling (Yokoyama and Malbon, 2009). Second attempt is designed to probe Wnt-dependent assembly of Dvlsbased supermolecular complexes. Dishevelled-based "punctae" had been observed earlier by fluorescence microscopy. These "punctae" have been shown to be the assemblies of protein and the size and cellular distribution changed in response to Wnt stimulation. The physical evidence for the existence for these putative "aggregates" or "punctae" of Dvl3based complexes was established using size-exclusion chromatography (SEC) technique, affinity pull-downs, proteomics, and fluorescent correlation microscopy ( $f c s)$. Dvl3-based complexes were interrogated physically in vitro by SEC analysis of cell extracts and in vivo by $f(s$ analysis in live cells (Yokoyama et al., 2010). Establishment of physical nature and 
dynamic character of the Dvls-based complexes is the key to understand Wnt signaling. For the first time, the assembly of supermolecular Dvl3-based complexes is shown in response to Wnt3a. Peak fractions (Dvl3-based supermolecular complexes) separated by SEC were subjected to LC-ESI-MS-MS. To avoid eliminating potential contamination of proteins/complexes, analysis was carried out at distinct time points. These approaches identified both expected and also novel components.

\section{Proteomic analysis of Dvls-based multiprotein complexes}

Wnt signaling is spatially and temporally transduced through the assembly of dynamic multiprotein complexes. Dvls, scaffold proteins, provide dynamic protein platform including protein kinases, phosphatases, receptors, adaptor molecules, and other signaling molecules. The Wnt home page provides an invaluable frame of Dvls interacting proteins (http://www.stanford.edu/ rnusse/wntwindow.html), although real Dvls-based complexes seem much more complicated. Recent measurement of the mass of Dvl3-based complexes showed that the MW of the complexes is $>2$ MegaDa by SEC and 35 MegaDa by fCS (Yokoyama et al., 2010). Structure and functional analysis of these Dvls-based supermolecular complexes is critical to understanding Wnt signaling. Proteomics provide a portal to identify complex partners assembled into signalsomes. In this study, two distinct approaches are employed.

\subsection{Analysis of Dvl2 interacting proteins using glutathione-S-transferase (GST) fusion protein pull down}

The pull-down technique is an invaluable tool for studying cellular pathways via proteinprotein interactions. GST fusion protein pull down experiments are one approach to identify interaction of between probe protein and unknown targets. GST fusion protein pulls down offers an important biological assay for direct protein-to-protein interactions. In this study, GST fusion proteins of Dvl2 domain are employed to discover novel Dvl2 interacting proteins. Identification of novel Dvls interacting proteins facilitates understanding the regulatory mechanism of Wnt signaling.

\subsubsection{Glutathione-S-transferase (GST) fusion protein pulls down}

GST fusion proteins of the conserved domains DIX, PDZ, and DEP and the putative SH3 binding domain of Dvl2 were immobilized on glutathione-derivatized agarose matrix. Immobilized GST-PDZ (aa 267-309), GST-DIX (aa 11-93), GST-DEP (aa 433-507), GSTputative SH3 binding containing region (aa 356-378) and GST itself (as a control) were incubated with cell lysates from F9 cells stimulated with or without Wnt 3a. The interacting proteins were pulled down and eluted from the beads. Eluted proteins were separated by immobilized $\mathrm{pH}$ gradient (IPG) strips ( $\mathrm{pH} 3-10$, first dimension separation) and subjected to second dimensional SDS-gel electrophoresis. Proteins were stained with SYPRO Ruby. Non specific proteins were eliminated by comparing gel patterns obtained with GST-Dv12 domains with those obtained by GST itself (fig. 1).

To identify Wnt-dependent interacting proteins, spots according in response to Wnt3a stimulation were excised from the gel (fig. 2), digested with trypsin overnight at $37{ }^{\circ} \mathrm{C}$ and analyzed by liquid chromatography electrospray ionization mass spectrometry (LC-ESI-MSMS, Applied Biosystems/MDS SCIEX) using a micro-column reverse phase HPLC interfaced to an LTQ ion trap mass spectrometer. Electrospray tandem mass spectrometry 
(-) Wnt3a

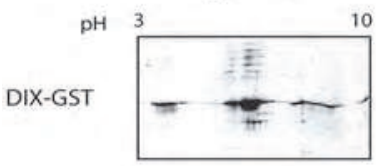

PDZ-GST

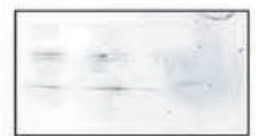

DEP-GST
(+) Wnt3a
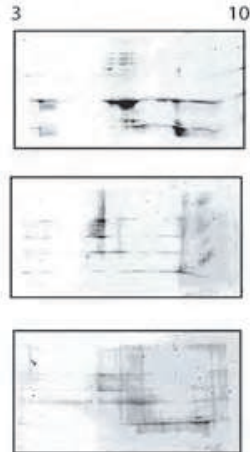

$(-)$ Wnt3a

$\mathrm{pH} 3$

SH3-GST

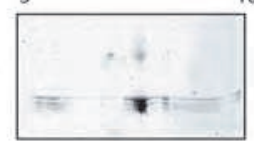

GST

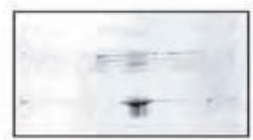

$(+)$ Wnt3a

103
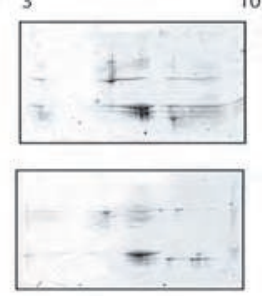

F9 cells were stimulated or unstimulated with Wnt3a for $30 \mathrm{~min}$. Cell lysates were incubated with either GST domain beads or GST beads for $15 \mathrm{~min}$. Bound proteins were eluted by SDS-running buffer and purified using ready prep 2-D cleanup kit. Samples were applied to pH 3-10 IPG strips, and then subjected to second dimensional gel electrophoresis.

Fig. 1. Second dimensional SDS-gel of GST pulls down.

\section{(+) Wnt3a}

DIX-pull down

$\mathrm{pH} 3$

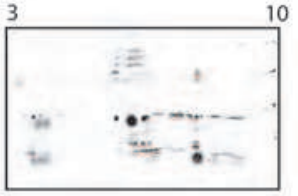

PDZ-pull down

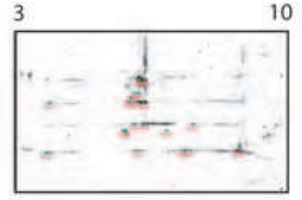

DEP-pull down

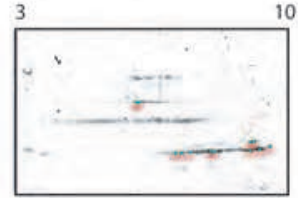

SH3-pull down

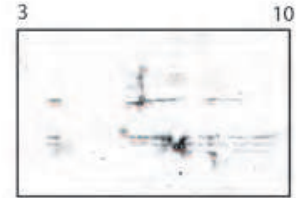

Wnt-dependent spots were selected by comparing gel patterns with or without Wnt stimulation. Spots with red numbers were further analyzed.

Fig. 2. Analysis of Wnt-dependent spots on a second dimensional gel.

based sequencing was performed. Data were analyzed by the Mascot search engine to identify amino acid sequences. LC-ESI-MS-MS analyses were performed at the Stony Brook Proteomics Center.

\subsubsection{Identification of Dvl2 interacting proteins}

The identified Dvl2 interacting proteins by GST fusion pull down are summarized in Table 1. Dvls are known to oligomerize via their DIX domain. Purified DIX domain polymerizes in vitro to form fibris and to puncta in vivo (Schwarz-Romond et al., 2005). DIX domain mediates dynamic polymerization platform with a high concentration of binding sites for Wnt signaling partners such as Axin and GSK3 $\beta$. Axin also has a DIX domain at the Cterminus which mediates self-interaction in a head to tail fashion, similar to Dvls (SchwarzRomond et al., 2007b; Schwarz-Romond et al., 2005). Known interacting proteins pulled down by the DIX domain-GST included all three Dvl isoforms and Axin2. Presence of PDZ and DEP peptides of Dvl2 in GST-DIX pulled down fraction demonstrated that Dvl2 forms homo oligomer. Dvl2 also forms complexes with the other two isoforms, Dvl1 and Dvl3; 


\begin{tabular}{|c|c|c|c|c|}
\hline Domain & Protein & $\begin{array}{l}\text { \# of independent } \\
\text { peptide identified }\end{array}$ & $\begin{array}{l}\text { \# of total } \\
\text { peptide }\end{array}$ & $\begin{array}{c}\% \text { sequence } \\
\text { coverage }\end{array}$ \\
\hline \multirow[t]{8}{*}{ DIX } & Dvl2 & 7 & 38 & 8 \\
\hline & Dvl1 & 6 & 14 & 6.9 \\
\hline & RGS18 & 2 & 5 & 6.8 \\
\hline & Dvl3 & 3 & 4 & 3.2 \\
\hline & $\begin{array}{l}\text { Rho-associated protein } \\
\text { kinase }\end{array}$ & 3 & 3 & 2.6 \\
\hline & PLK4 & 2 & 4 & 1.45 \\
\hline & Axin 2 & 2 & 2 & 2.42 \\
\hline & PTPRR & 1 & 1 & 0.8 \\
\hline \multirow[t]{7}{*}{ PDZ } & Tropomyosine $\alpha$ & 7 & 9 & 23.4 \\
\hline & Actin & 8 & 18 & 21.9 \\
\hline & Cyclin & 2 & 2 & 5.36 \\
\hline & $\begin{array}{l}\text { PKC and casein kinase } \\
\text { substrate in neuron } \\
\text { protein } 1\end{array}$ & 2 & 2 & 4.08 \\
\hline & Axin 2 & 1 & 1 & 1.42 \\
\hline & Axin 1 & 1 & 1 & 1.0 \\
\hline & B-Raf & 1 & 1 & 0.91 \\
\hline \multirow[t]{4}{*}{$\mathrm{DEP}$} & Actin & 6 & 14 & 18.1 \\
\hline & Adenylate kinase 1 & 2 & 2 & 8.76 \\
\hline & $\begin{array}{l}\text { Ubiquitin-conjugating } \\
\text { enzyme E2M }\end{array}$ & 1 & 1 & 4.91 \\
\hline & Cyclin & 1 & 1 & 3.7 \\
\hline \multirow{8}{*}{$\begin{array}{l}\mathrm{SH} 3 \\
\text { binding }\end{array}$} & Tropomyosine $\alpha$ & 8 & 12 & 22.6 \\
\hline & Actin & 12 & 46 & 31 \\
\hline & HSP 70K & 3 & 4 & 5.6 \\
\hline & PARD-3 & 2 & 14 & 1.56 \\
\hline & Desmoplakin-3 & 3 & 3 & 1.0 \\
\hline & Junction plakoglobin & 2 & 2 & 3.4 \\
\hline & $\begin{array}{l}\text { Rho-associated protein } \\
\text { kinase }\end{array}$ & 2 & 8 & 1.0 \\
\hline & Cullin 3 & 1 & 1 & 1.3 \\
\hline
\end{tabular}

Table 1. Identified Dvl2 interacting proteins.

demonstrating Dvls assemble Dvls-based complexes and thus provide a Dvls platform. Polo-like kinase 4 (PLK4), Regulator of G protein signaling (RGS) 18, Rho-associated protein kinase and Receptor-type protein tyrosine phosphatase R (PTPRR) were identified as novel DIX domain interacting proteins.

PDZ domain beads pulled down interacting proteins Axin1 and Axin2. Novel interacting proteins were Tropomyosine $\alpha$, cyclin, PKC and casein kinase substrate in neuron protein 1 and B-Raf proto-oncogen serine/threonine kinase. Adenylate kinase 1, cyclin and ubiquitinconjugating enzyme E2M were identified as novel DEP domain interacting proteins. SH3 
binding domain pulled down Tropomyosine $\alpha$, HSP 70K, PARD-3, desmoplakin-3, plakoglobin, Rho-associated protein kinase, and Cullin 3. Actin, known Dvl interacting protein, was pulled down by PDZ, DEP and SH3 binding domains of Dvl2.

\subsubsection{Assay for Lef/Tcf-sensitive transcription}

Lef/Tcf-sensitive transcription is the read out of Wnt/beta-catenin signaling pathway. F9 cells were grown on 12-well plates and co-transfected with rat Fz1 (Rfz1) and Super8xTOPFlash (M50) (Seto and Bellen, 2006). After 1-2 days of transfection, cells were treated with Wnt3a $(20 \mathrm{ng} / \mathrm{ml})$ for up to 8 hours. Cells were lysed in a reporter gene lysis buffer [12.5 mM Tris- $\mathrm{H}_{3} \mathrm{PO}_{4} \mathrm{pH}$ 7.8, $1 \mathrm{mM}$ trans-1, 2-cyclohexanediaminetetraacetic acid (CDTA), 2 mM DTT, 10\% glycerol and $1 \%$ Triton X-100] (Promega) and further analyzed. Lef/Tcf-sensitive transcription activity was determined using cell lysates according to the manufacture's instructions (Stratagene) and displayed to relative to unstimulated cells (set to " 1 ").

\subsubsection{Evaluation of novel Dvl2 interacting proteins}

Dvl proteins are phosphorylated in response to Wnt and display a shift of electrophoretic mobility on SDS-PAGE. Dvl activity itself is reported to be controlled by multiple phosphorylation events (McKay et al., 2001; Sun et al., 2001; Willert et al., 1997). Thus, Dvl phosphorylation is implicated in the Wnt signaling pathway. Many serine/threonine protein kinases and phosphatases are known to interact with Dvls. CK1ع, CK2 and Par1 are proposed to phosphorylate Dvls (Cong et al., 2004; Sun et al., 2001; Willert et al., 1997). Not only serine/threonine kinases, but also Src family tyrosine kinases phosphorylate Dvl2 (Yokoyama and Malbon, 2009). Protein phosphatase 2C (PP2C) and protein phosphatase 2A (PP2A) dock to Dvls (Strovel et al., 2000; Yokoyama and Malbon, 2007).

Treatment with okadaic acid (chemical inhibitor of serine/threonine phosphatases, PP1 and PP2A) mimics Wnt 3a action, increasing the cellular abundance of Axin and GSK3 $\beta$ and $\beta$ catenin as well as the trafficking of signaling elements in Wnt/ $\beta$-catenin signaling pathway. Although mimicking effects of Wnt3a on the cellular abundance and trafficking of key signaling elements in Wnt / $\beta$-catenin signaling, suppression of PP2A alone does not provoke activation of Lef/Tcf-sensitive transcription, but potentiates its activation by Wnt3a. PP2A activity declines dramatically after Wnt stimulation and direct binding of Dvl2 to PP2A suppresses a phosphatase activity. PP2A dephosphorylates Dv12 (Yokoyama and Malbon, 2007). Thus, phosphorylation-dephosphorylation is a central regulatory mechanism of docking proteins-Dvls interaction.

Consistent with the critical roles of phosphorylation-dephosphorylation in Wnt signaling pathway, several kinases and phosphatase were identified as novel Dvl2 interacting proteins. One tyrosine phosphatase PTPRR and two serine/threonine kinases, PLK4 and BRaf, were further analyzed to confirm their functions in the Wnt/ $\beta$-catenin signaling pathway.

Receptor-type protein tyrosine phosphatase R (PTPRR), also known as PTP-SL, contains a kinase interacting motif (KIM), located just N-terminal of the phosphatase domain, and associates with the mitogen-activated protein (MAP) kinase. PTPRR associates with MAPKs and inactivates kinases by dephosphorylating tyrosine residue (Hendriks et al., 2009). MAPKs promote Wnt/ $\beta$-catenin signaling pathway via LRP6 phosphorylation suggesting convergence between Wnt/ $\beta$-catenin signaling pathway and the mitogenic pathway 
(Cervenka et al., 2011). F9 cell extracts from stimulated or unstimulated cells were incubated with GST beads or one of the distinct GST-domain beads. PTPRR displayed prominent docking to DIX and DEP domains, modestly to the PDZ domain and weakly to the putative SH3 binding domain. Wnt stimulation slightly enhanced docking of PTPRR to Dvl2 DIX domain (fig. 3A). Association of Dvl2 and PTPRR was confirmed by Dvl2 immunoprecipitation followed by proved with either anti-Dvl2 antibody or anti-PTPRR antibody. Association of Dvl2 and PTPRR was enhanced by Wnt3a in a time-dependent manner (fig. 3B). Docking of PTPRR to Dvl2 increased over 1hour post Wnt3a stimulation. The functional role of PTPRR in Wnt/ $\beta$-catenin pathway was investigated by measuring Lef/Tcf-sensitive transcriptional activity, a hallmark of activation of the Wnt/ $\beta$-catenin pathway, by knocking down of PTPRR. siRNA mediated knockdown of PTPRR resulted in enhancement of Lef/Tcf-sensitive transcription activity, while overexpression of PTPRR attenuated Lef/Tcf-sensitive transcription activity (fig. 3C and 3D) confirming that PTPRR is a novel Dvl2 interacting protein and functions as a negative regulator of the $\mathrm{Wnt} / \beta$-catenin signaling pathway. Association of tyrosine phosphatase with Dvl2 is a novel finding.

Polo-like kinase 4 (PLK4) is another novel DIX domain interacting protein which was identified in this study. PLK4 is the most structurally divergent Polo family kinase and is essential for mouse embryonic development (Swallow et al., 2005). PLK4 is required for the reproduction of centrosomes during cell cycle (Habedanck et al., 2005). Interaction of PLK4 and Dvl2 was confirmed by co-immunoprecipitation with an anti-Dvl2 antibody. Lef/Tcfsensitive transcription was enhanced by knockdown of PLK4, while overexpression of PLK4 attenuated Lef/Tcf-sensitive transcription, suggesting negative roles of PLK4 in Wnt/ $\beta$ catenin signaling pathway (fig. 3E, 3F and 3G). Thus PLK4 is evaluated as functional novel interacting protein of Dvl2.

B-Raf proto-oncogen serine/threonine kinase, which transduces signals from Ras to MEK and ERK/MAPK, was identified as a novel PDZ interacting protein. These pathways regulate many cellular functions, including cell proliferation, differentiation, apoptosis, motility and metabolism (Wellbrock et al., 2004); and implicated in many human diseases such as cancer. (Rapp et al., 2006). Docking of B-Raf to PDZ domain was regulated by Wnt3a (fig. 4A). DIX, DEP and putative SH3 binding domains were also involved in the interaction of the two molecules. Docking of B-Raf to Dvl2 was Wnt-dependent and dramatically increased $15 \mathrm{~min}$ after Wnt3a stimulation. The association persisted for 2hours (fig. 4B). Attenuation of Lef/Tcf-sensitive transcription by knocking down of B-Raf demonstrated that B-Raf regulates positively Wnt/ $\beta$-catenin signaling pathway (fig. 4C). Dose-dependent enhancement of Lef/Tcf-sensitive transcription is occurred by expression of B-Raf (fig. 4D).

Thus, the newly identified Dvl2 interacting proteins, PTPRR, PLK4 and B-Raf are indeed docked to Dvl2 in a Wnt- and time-dependent manner and, regulate Wnt pathway either negatively (PTPRR and PLK4) or positively (B-Raf).

\subsection{Tyrosine phosphorylation of Dvl2 regulates Wnt/ $\mathrm{W}$-catenin signaling pathway}

Dvl proteins are highly phosphorylated in response to Wnt stimulation and Wnt-dependent phosphorylation sites on Dvls have been poorly analyzed. Dvl phosphorylations regulate the Wnt signaling pathway, especially with regard to serine/threonine protein kinases (Kishida et al., 2001; Yanagawa et al., 1995). Involvement of tyrosine kinases in Wnt signaling pathway has not been established, except tyrosine phosphorylation of $\beta$-catenin. The phosphorylation sites on Dvls are presumably many and several mechanisms of Dvls 
A

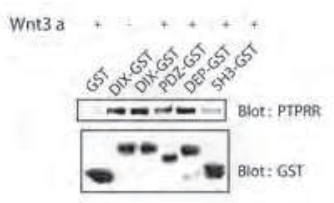

C

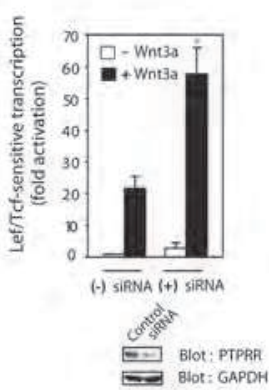

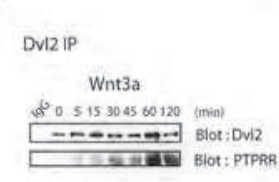

D

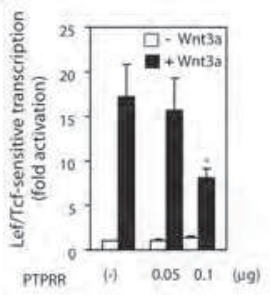

$E$

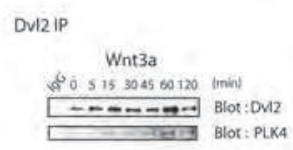

$\mathrm{F}$

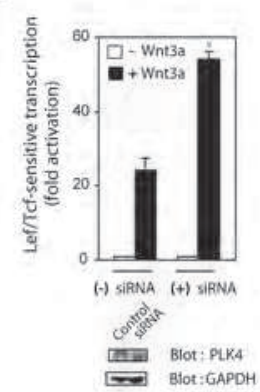

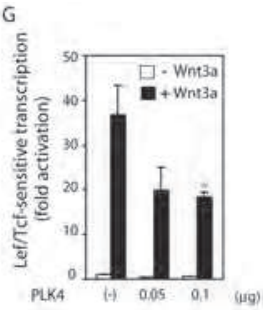

A-D, analysis of PTPRR in Wnt/ $\beta$-catenin signaling pathway. E-G, analysis of PLK4 in Wnt/ $\beta$-catenin signaling pathway.

(A) PTPRR docks to Dvl2. Lysates from cell treated or untreated with Wnt3a were incubated with one of the immobilized Dvl2 domains or GST itself. Bound proteins were analyzed by SDS-PAGE and immunoblotting with either anti-PTPRR or anti-GST antibody.

(B) Time course of the association of Dvl2 and PTPRR. Cell lysates were immunoprecipitated with antiDvl2 antibody. Bound proteins were analyzed by SDS-PAGE and immunoblotting with either anti-Dvl2 or anti-PTPRR antibody.

(C) Effect of knockdown of PTPRR on Lef/Tcf-sensitive transcription. F9 cells were transfected with siRNA targeting PTPRR one day before co-transfection of the cells with Rfz1 and Super8xTOPFlash reporter (M50). On the following day, the cells were stimulated with Wnt3a for 7 hours and cell lysates were assayed for Lef/Tcf-sensitive transcription. Statistical significance is indicated $\left({ }^{*}, p<0.005\right)$. Cell lysates were analyzed by immunoblotting with either anti-PTPRR or anti-GAPDH antibody (as a control).

(D) Overexpression of PTPRR attenuates Wnt3a-sensitive Lef/Tcf-sensitive transcription. F9 cells were co-transfected with Rfz1, M50, and a PTPRR expression vector one day before cells were stimulated without or with purified Wnt3a for 7 hours. Cell lysates were assayed for Lef/Tcf-sensitive transcription activity. Statistical significance is indicated $\left({ }^{*}, p<0.05\right)$.

(E) Dvl2 docks to PLK4 in a Wnt- and time-dependent manner. Cell lysates were subjected to immunoprecipitation with anti-Dv12 antibody and analyzed by SDS-PAGE and then immunoblotted with either anti-Dvl2 antibody or anti-PLK4 antibody.

(F) Knockdown of PLK4 enhances Lef/Tcf-sensitive transcription. F9 cells were transfected with siRNA targeting PLK4 one day before co-transfection of the cells with Rfz1 and M50. On the following day, the cells were stimulated with Wnt3a and assay for Lef/Tcf-sensitive transcription was performed as described previously. Statistical significance is indicated $\left({ }^{*}, p<0.005\right)$

(G) Overexpression of PLK4 attenuates Lef/Tcf-sensitive transcription. Cells were co-transfected with PLK4, Rfz1 and M50 for one day before Wnt stimulation. Assay for Lef/Tcf-sensitive transcription was performed. Statistical significance is indicated $\left({ }^{*}, p<0.005\right)$.

Fig. 3. Analysis of novel Dvl2 interacting proteins. 
A

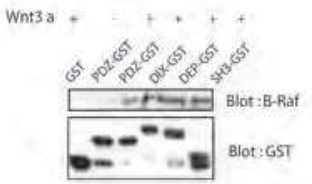

B

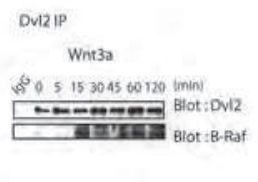

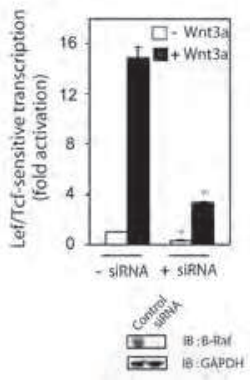

D

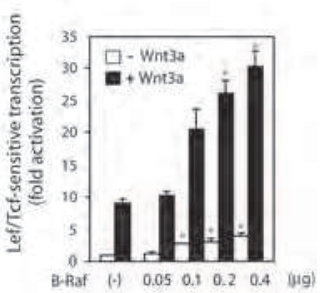

(A) B-Raf docks to Dvl2. Lysates from cells treated or untreated with Wnt3a were incubated with either GST itself or one of the immobilized Dvl2 domains. Bound proteins were proved with either anti-B-Raf antibody or anti-GST antibody.

(B) Time course of the association of Dvl2 and B-Raf. Cell lysates were subjected to Dvl2 immunoprecipitation. Bound proteins were analyzed by SDS-PAGE and immunoblotting with either anti-Dvl2 antibody or anti-B-Raf antibody.

(C) Effect of knockdown of B-Raf on Lef/Tcf-sensitive transcription. F9 cells were transfected with siRNA targeting B-Raf one day before co-transfection of the cells with Rfz1 and M50. On the following day, the cells were stimulated and Lef/Tcf-sensitive transcription was assayed. Statistical significance is indicated $\left({ }^{*}, p<0.005\right)$. Cell lysates were analyzed by immunoblotting with either anti-B-Raf antibody or anti-GAPDH antibody (as a control).

(D) Overexpression of B-Raf enhances Wnt3a-sensitive Lef/Tcf-sensitive transcription. F9 cells were cotransfected with Rfz1, M50, and B-Raf expression vector one day before cells were stimulated with or without purified Wnt3a for 7 hours. Cell lysates were assayed for Lef/Tcf-sensitive luciferase transcription activity. Statistical significance is indicated $\left({ }^{*}, p<0.005\right)$.

Fig. 4. Analysis of B-Raf in Wnt/ $\beta$-catenin signaling pathway.

phosphorylation may be involved; distributive phosphorylation, sequential priming phosphorylation, processive phosphorylation, and combination of distributive phosphorylation/sequential priming phosphorylation or processive phosphorylation. Similar to LRP5/6, several kinases may phosphorylate same sites on Dvls. Dvl kinases may play multiple opposing roles in Wnt signaling pathway like CK1 and GSK3 $\beta$ do. Thus, regulations by phosphorylation in Wnt signaling pathway are a complicated process, since many important molecules in the pathway are positively or negatively regulated by phosphorylation. To avoid such a complexity, in vitro systems are employed, although functional and physiological analysis in vivo is required. The amino acid region 370-376 of Dvl2 displays a consensus sequence for a class I core SH3 protein-binding motif RTEPVRP (Penton et al., 2002). This region is conserved in all three mammalian isoforms of Dvl suggesting that tyrosine phosphorylation may be functional in Dvl biology and Wnt signaling. In developmentally relevant signaling, Src is reported to elevate the expression (Karni et al., 2005) and phosphorylation at Tyr Y654 of $\beta$-catenin. The phosphorylation of Tyr654 blocked the E-cadherin- $\beta$-catenin interaction (Roura et al., 1999). In addition to Src, other tyrosine kinases such as Fyn, Fer, transmembrane tyrosine kinase EGFR and c-Met, downregulate E-cadherin-mediated adhesion via enhanced tyrosine phosphorylation of $\beta$ catenin (Lilien and Balsamo, 2005; Piedra et al., 2001). In chronic myeloid leukemia cells, oncogenic tyrosine kinase $\mathrm{Bcr}-\mathrm{Abl}$ triggers tyrosine phosphorylation of $\beta$-catenin, stabilizes $\beta$-catenin levels and enhances nuclear signaling activation (Coluccia et al., 2007). A possible 
involvement of tyrosine kinases, particularly Src family tyrosine kinases, in Wnt/ $\beta$-catenin signaling pathway was investigated.

\subsubsection{Baculovirus expression and purification of Dvl2}

Baculovirus/Sf9 cell system was employed to express Dvl2. Full length Dvl2 was subcloned into plasmid pBACgus-9 (N-terminal T7 tag and C-terminal CBD-tag and poly Histidinetag, Novagen), and expressed in Sf9 cells using the Bac Vector-3000 DNA transfection kit (Novagen). Sf9 cells were grown in Ex-cell-401 medium supplemented with L-glutamine and $2.5 \%$ fetal bovine serum. Sf9 cells were infected with recombinant Dvl2 baculovirus at a MOI (multiplicity of infection) of 5. Cells were harvested after 4 days of infection and lysed in a French pressure cell twice in $20 \mathrm{mM}$ Tris- $\mathrm{HCl}$ buffer $(\mathrm{pH} 8.0)$ containing $1 \%$ deoxycholate, $2 \mathrm{mM} \mathrm{Na}_{3} \mathrm{VO}_{4}, 20 \mathrm{mM} \mathrm{NaF}, 5 \mathrm{mM}$ 2-mercaptoethanol, $10 \mu \mathrm{g} / \mathrm{ml}$ leupeptin, $10 \mu \mathrm{g} / \mathrm{ml}$ aprotinin, and $1 \mathrm{mM}$ phenylsulfonyl fluoride (PMSF). After centrifugation, rDvl2 was purified by $\mathrm{Ni}^{2+}$-affinity chromatography.

\subsubsection{Phosphorylation of Dvl2 by Src family kinase and identification of tyrosine phosphorylation sites on Dvl2}

Phosphorylation of rDvl2 was performed in a kinase buffer $(10 \mathrm{mM}$ Tris- $\mathrm{HCl}, \mathrm{pH} 7.4,10 \mathrm{mM}$ $\mathrm{MgCl}_{2}, 10 \mathrm{mM} \mathrm{MnCl} 2,1 \mathrm{mM} \mathrm{Na} \mathrm{VO}_{4}, 50 \mathrm{mM} \mathrm{NaF}, 0.5 \mathrm{mM}$ ATP) with purified rSrc (from Sf9 cell) for 1 hour at $30^{\circ} \mathrm{C}$. Phosphorylated rDvl2 was digested with trypsin and subjected to analysis using API QSTAR Pulsar LC/MS/MS (Applied Biosystems/MDS SCIEX) equipped with a Protana nanospray source (Protana Engineering A/S) and an UltiMate capillary high pressure liquid chromatography (LC Packings) with a PepMap $\mathrm{C}_{18}$ nanocolumn (75 $\mu \mathrm{m} \times 15 \mathrm{~cm}$, LC Packings). Phosphopeptides were detected by a data base search using Pro ID software (Applied Biosystems/MDS SCIEX).

\subsubsection{Functional analysis of tyrosine phosphorylation on Dvl2}

The functional relevance of the detected tyrosine phosphorylation sites was assessed following site-directed mutagenesis using Qickchange Mutagenesis system (Stratagene). The functional ability of the mutational constructs (YF mutants of Dvl2; Y18F, Y27F, Y275F, Y295F and Y463F) analyzed by Lef/Tcf-sensitive transcription in Dvl2-deficient cells. F9 cell stably expressing Rfz1 and M50 were transfected with siRNA targeting Dvl2 one day before transfection of cells with either wild-type or an YF mutant of Dvl2. On the following day, cells were stimulated with Wnt3a for 7 hours and Lef/Tcf-sensitive transcription was assayed.

\subsubsection{Dvl2 docks to and activates Src in a Wnt-dependent manner}

F9 cell extracts were incubated with immobilized Dvl2 domains (GST-DIX, GST-DEP, GSTPDZ, GST-putative SH3 binding site, and GST-C-terminus of Dvl2). Src family kinases (Src and Hck) displayed prominent docking on the putative SH3 binding region (aa 356-378) and the proline-rich region of the C-terminus of Dvl2 (aa 511-736) (fig. 5A). The ability of the $\mathrm{SH} 3$ domains of Src family tyrosine kinases, but not Nck SH3 domain to enable docking to Dvl2 reflects the specificity of the scaffold-kinase interaction (Yokoyama and Malbon, 2009). Positive roles of Src family tyrosine kinases in the Wnt/ $\beta$-catenin signaling pathway were confirmed by either treatment with an inhibitor of the Src family tyrosine kinases (PP2) or with a siRNA-induced knockdown of Src. Treatment with PP2 or siRNA targeting Src 
attenuated the formation of primitive endoderm (another readout of Wnt signaling pathway) as well as Lef/Tcf-sensitive transcription (Yokoyama and Malbon, 2009). Analysis of phosphorylation sites on Dvl2 by Src was performed in vitro. Purified rDvl2 from Sf9 cell was phosphorylated by a Src family kinase. The five tyrosine residues (Y18, Y27, Y275, Y295 and Y463) were identified by mass spectrometry. One example was shown in fig. 5B. Src family tyrosine kinases can phosphorylate in vitro two tyrosine residues (Y18 and Y27) of the DIX domain, two residues (Y275 and Y295) of the PDZ domain, and a single residue (Y463) in the DEP domain. Dvl2 levels were knocked-down by siRNA targeting Dvl2; the ability of YF mutants (Dv12 Y18F, Y27F, Y275F, Y295F and Y463F) versus wild-type Dvl2 to rescue Wnt3a-stimulated Lef/Tcf-sensitive transcription was probed. Expression of the wild-type Dvl2 in Dvl2 knockdown cells restored the Wnt3a-stimulated Lef/Tcf-sensitive transcription, whereas the $\mathrm{Y} 18 \mathrm{~F}$ Dvl2 mutant in particular attenuated the response by more than $50 \%$ (fig. 5C).

A

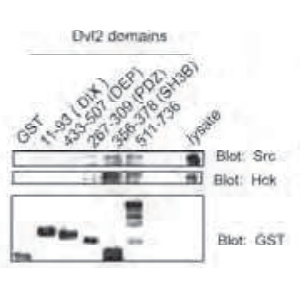

B

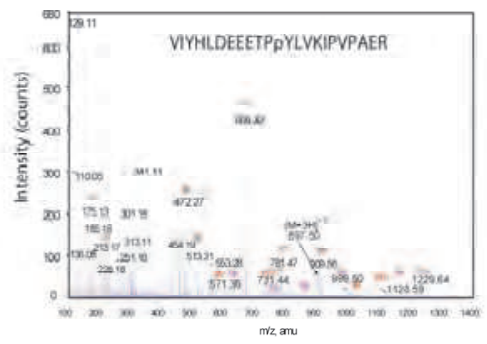

C

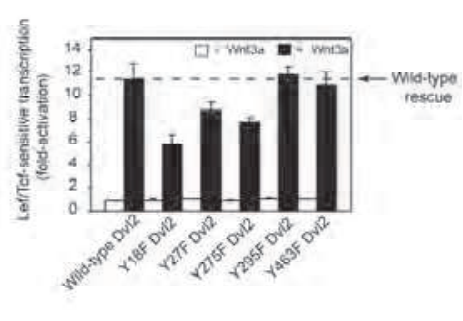

(A) Dvl2 docks to Src and Hck tyrosine kinases. Cell lysates were incubated with one of the immobilized Dvl2 domain, DIX, DEP, PDZ, putative SH3 binding region (SH3B), C-terminus (aa 511736) and GST itself. Proteins docking to the Dvl2 domains were resolved by SDS-PAGE and analyzed by immunoblotting, staining with: anti-Src, anti-Hck, and anti-GST antibodies (loading control).

(B) Mass spectrum of the Y27 phosphopeptide. Phosphorylated Dvl2 was digested with trypsin and analyzed by LC/MS/MS. Tyrosine 27 was identified as phosphorylation site.

(C) Tyrosine-to-phenylalanine substitution mutants of Dv12 attenuate Lef/Tcf-sensitive transcription. F9 cells stably expressing Rfz1 and M50 were transfected with siRNA targeting Dvl2 one day before transfection of the cells with either wild-type or one of the YF-mutants of Dvl2 (Y18F, Y27F, Y275F, Y295F and Y463F). On the following day, cells were stimulated with Wnt3a. Assay for Lef/Tcf-sensitive transcription was performed. Data are adapted with permission from the publication (Yokoyama, N. \& Malbon, C. C. (2009). J Cell Sci 122, 4439-4451).

Fig. 5. Src family tyrosine kinases are involved in Wnt/ $\beta$-catenin signaling.

At least two prominent components of the multiprotein complexes, Dvl2 and $\beta$-catenin, were phosphorylated on tyrosine residues in response to Wnt stimulation. Tyrosine phosphorylation of Y18, Y27 and Y275 of Dv12 appears to contribute, in some complex manner, to the ability of Src to enhance Wnt3a/ $\beta$-catenin signaling. Wnt stimulated Src docking to Dvl2 through the SH3-binding domain and the C-terminus proline-rich domain. Src activity is regulated by intramolecular interactions, an interaction between the $\mathrm{SH} 2$ domain and the C-terminal tail as well as an interaction between the $\mathrm{SH} 3$ domain and a polyproline-type helix in the SH2-kinase linker region (Sicheri et al., 1997; Williams et al., 
1997; Xu et al., 1997). Docking of Src to Dvl2 SH3 binding domain and C-terminus proline--rich domain disrupts Src autoinhibition, therefore enabling phosphorylation of Src substrates (Brown and Cooper, 1996; Miller, 2003). Activated Src enhances Wnt activation of the canonical pathway via phosphorylation of Dvl2 and $\beta$-catenin (Yokoyama and Malbon, 2009). Many Src family kinase substrates themselves possess SH2 and/or SH3 ligands, which couple enzyme activation to substrate phosphorylation (Brown and Cooper, 1996; Miller, 2003; Porter et al., 2000). In deed, total Src activity was increased after Wnt stimulation. Dvl2 bound form of Src showed higher activity than that of free form of Src. Furthermore, knockdown of Dvl2 blocked Wnt3a-induced activation of Src. Previously Y27D mutant of Dvl2 was shown as a polymerization defective mutant (Schwarz-Romond et al., 2007a). Roles of tyrosine residues Y18 and Y27 are the keenest interest. The tyrosine residue in the DIX domain plays an important role in polymerization of Dvl (i.e., form punctae). Application of GST pulled down and proteomics led to discover novel positive roles of Src family tyrosine kinase in Wnt/ $\beta$ catenin signaling (Yokoyama and Malbon, 2009).

\subsection{Assembly of Dvls-based supermolecular complexes in response to Wnt stimulation}

Establishment of the physical nature and dynamic character of the Dvls-based complexes is a key to understanding Wnt signaling. The second approach is designed to probe Wntdependent assembly of Dvls-based supermolecular complexes. Dishevelled-based "punctae" have been observed earlier by fluorescence microscopy. Wnt treatment resulted in change of size of the "punctae" as well as their cellular localization. The physical evidence for the existence of these putative "aggregates" or "punctae" of Dvl3-based complexes was established using size-exclusion chromatography (SEC), affinity pull-downs, proteomics, and fluorescent correlation microscopy ( $f(s)$. Dvl3-based complexes were interrogated physically in vitro by SEC analysis of cell extracts and in vivo by $f c s$ analysis in live cells (Yokoyama et al., 2010). Fcs enabled to analyze single molecules in live cells and is exploited for the study of the signalsomes mass and dynamic mobility. For the first time, assembly of supermolecular Dvl3-based complexes was shown in response to Wnt3a. Proteomics dissected the compositions of Dvls-based supermolecular complexes in response to Wnt stimulation.

\subsubsection{Preparation of Dvl3-based supermolecular complexes and quantification of proteins}

F9 cells co-expressing rat fz1(Rfz1) were suspended in ice-cold buffer $(20 \mathrm{mM}$ Tris- $\mathrm{HCl} \mathrm{pH}$ 8.0, $0.2 \mathrm{M} \mathrm{NaCl}, 1 \% \mathrm{NP}-40,1 \mathrm{mM}$ PMSF, $10 \mu \mathrm{g} / \mathrm{ml}$ leupeptin, and $10 \mu \mathrm{g} / \mathrm{ml}$ aprotinin) and disrupted by repeated passage through a 23-gauge needle, and then centrifuged to remove unbroken cells, nucleus and mitochondria. Supernatants were filtered $(0.45 \mu \mathrm{m})$ and diluted with buffer without detergent. $20 \mathrm{mg}$ proteins were applied to a Superdex 200 gel filtration column (HiLoad Superdex TM 200 prep grade 26/60, fast-performance liquid chromatography system AKTA, GE Healthcare) which was preequilibrated with $20 \mathrm{mM}$ Tris- $\mathrm{HCl}(\mathrm{pH} 8.0), 0.2 \mathrm{M} \mathrm{NaCl}$, and $10 \%$ glycerol. Each fraction was analyzed by SDS-PAGE and Western immunoblotting. Protein concentration was determined by use of the Bradford assay. The immunoreactive bands were scanned by calibrated Umax 1000 scanner equipped with SilverFast software (LaserSoft Imaging Inc.). The bands were quantified by using Aida software (Raytest, Germany). 


\subsubsection{High-performance size-exclusion analysis of Dvls-based supermolecular complexes}

Size-exclusion chromatography (SEC) is one of the approaches for separating protein mixtures into numerous clusters of reduced complexity. Separation of Dvl3-based signalsomes was established by SEC for the first time. Cell lysates prepared from cells stimulated with or without Wnt3a were subjected to size-exclusion column chromatography. This high-pressure column (very long and well packed, HiLoad Superdex TM 200 prep grade 26/60) permitted high resolution over a $M_{r}$ range of $43 \mathrm{kDa}$ to 2.0 MegaDa (i.e., 2,000,000 daltons). The operation was carried out with AKTA system (GE Healthcare). Molecular weight standards showed excellent and reproducible peak separation. The identified peaks are, discrete and highly reproducible $M_{r}$ (fig. 6A). Thus size-exclusion column chromatography allows separation of Dvls-based supermolecular complexes for a reproducibly and accurate. Individual fractions were subjected to SDSPAGE and analyzed by immunoblotting with isoform-specific antibodies. Dv12, the major isoform of Dvls in F9 cell (>95\%), displayed two major peaks (one with a peak $M_{r}$ of $\sim 1.6$ MegaDa, and other centered around 0.5 MegaDa- $\left.M_{r}\right)$, and a minor peak ( 80 kDa of $\left.M_{r}\right)$, likely a monomeric Dvl2. Dvl1 revealed the two similar high- $M_{r}$ supermolecular forms of 1.6 and 0.5 MegaDa- $M_{r}$. In contrast, Dvl3 supermolecular complexes appeared a broad peak and the $M_{r}$ of the resolved complexes spanning from the homodimeric Dvl3 (150-210 kDa) to the well-defined peaks with $M_{r}$ from 0.8 to $2.0 \mathrm{MegaDa}$ (fig. 6B). All three Dvls isoforms migrated to $\sim 2$ MegaDa regions without Wnt stimulation. GSK3 $\beta$ and Axin, components of the Dvls-based supermolecular complexes, also migrated to similar positions (Yokoyama et al., 2010).

\subsubsection{Wnt stimulation provokes assembly of dynamic Dvl3-based supermolecular complexes}

To address the functional significance of Dvls-based supermolecular complexes, we investigated whether their formation was regulated by Wnt3a stimulation. As seen in fig. 7A and $7 \mathrm{~B}$, Wnt3a provoked a dramatic shift in the apparent $M_{r}$ of the Dvl3-based complexes to populations with sharply larger masses $\left(>2.0\right.$ MegaDa- $\left.M_{r}\right)$. The abundance of Dvl3 based complexes (>2.0 MegaDa- $M_{r}$ ) was increased in a time-dependent manner (30min-60min after Wnt 3a stimulation) (fig. 7A and 7B). The upfield shift of Dvl3-based supermolecular complexes, derived at the expense of lower- $M_{r}$ peaks, was detected as early as 5 min postWnt3a stimulation (unpublished data). In contrast, the shifts of other two isoforms, Dvl1 and Dvl2, to $>2.0$ MegaDa- $M_{r}$ were relatively small in response to Wnt. Dvl1/2-based complexes did not approach the limit size of those formed by Dvl3-based complexes. GSK3 $\beta$ and Axin also migrated with supermolecular complexes of increasing apparent mass (>2 MegaDa- $M_{r}$ ) in response to Wnt3a stimulation for 30 min (Yokoyama et al., 2010).

To ascertain whether mimicking Wnt3a action could result in the assembly of Dvl3-based supermolecular complexes, several distinct approaches were employed. The first approach is overexpression of Dvls. Assembly of Dvl3-based supermolecular complexes varied with the isoform of Dvls. It is known that overexpression of Dvl1 and Dvl3 in mouse F9 cells stimulated Lef/Tcf-sensitive transcription (Lee et al., 2008). Overexpression of Dvls provoked the formation of very large, Dvl3-based supermolecular complexes (fig. 7C), even larger than those observed in response to Wnt3a (fig. 7B). Overexpression of Dvl1 stimulated both activation of the canonical Lef/Tcf-sensitive transcription and an increase in the formation of the very large $\left(>2.0 \mathrm{MegaDa}-M_{r}\right)$ Dvl3-based supermolecular complexes 
A

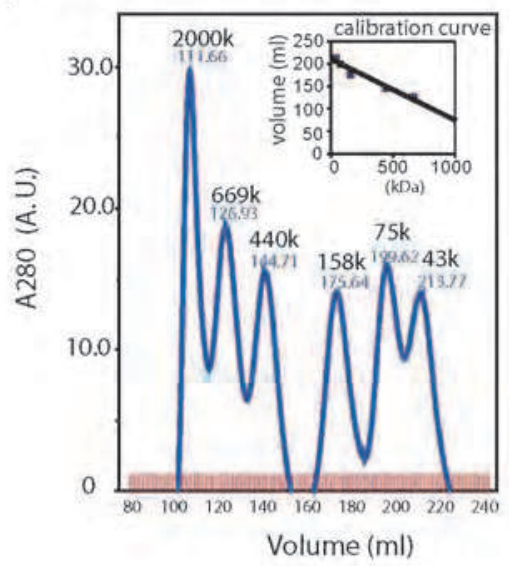

B

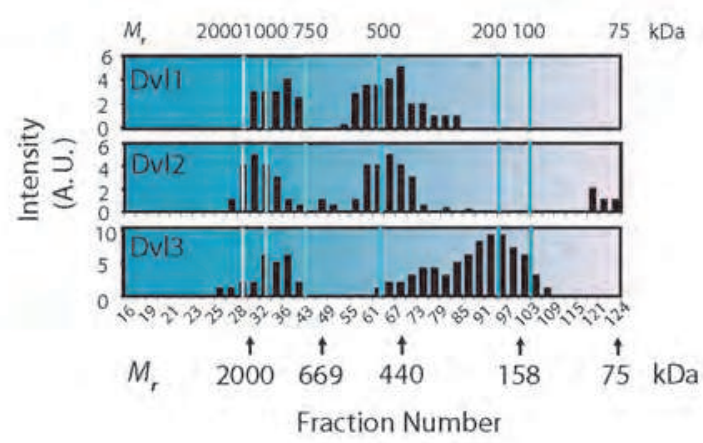

(A) Resolution of Superdex 200 column. Mixtures of molecular weight markers (Blue Dextran 2000, thyroglobulin, ferritin, aldolase, conalbumin and ovaalbumin) were applied to Superdex 200 column. The elution profile was monitored by absorbance at $280 \mathrm{~nm}$.

(B) F9 cells expressing Rfz1 were disrupted and cell lysates were applied to the Superdex 200 column. Proteins were analyzed by SDS-PAGE and immunoblotted with Dvl isoform-specific antibodies. Blots were quantified by the calibrated scanner. The calculated, relative molecular weight $\left(M_{r}\right)$ positions from the calibration curve are labeled at the top, fraction numbers on the bottom. Arrows indicate the precise position at which calibration proteins elute from the Superdex 200 column. Data are adapted with permission from the publication (Yokoyama, N., Golebiewska, U., Wang, H. Y. \& Malbon, C. C. (2010) J Cell Sci 123, 3693-3702).

Fig. 6. Separation of Dvls-based supermolecular complexes using size-exclusion column chromatography.

(fig. 7C and Table 2). Overexpression of Dvl3 provoked a prominent activation of Lef/Tcfsensitive transcription and a sharp increase in the formation of very large ( $>2.0$ MegaDa- $\left.M_{r}\right)$ Dvl3-based complexes (fig. 7C and Table 2). In contrast, overexpression of the most abundant Dvl isoform (i.e., Dvl2 which constitutes $>95 \%$ of Dvls in F9 cell) provoked only a modest Lef/Tcf-sensitive transcriptional response and little formation of the very large, (>2.0 MegaDa- $M_{r}$ ) Dvl3-based complexes (fig. 7C and Table 2). Thus, the formation of the very large Dvl3-based supermolecular complexes can be specifically mimicked by the overexpression of either Dvl1 or Dvl3, which can uniquely activate the Lef/Tcf-sensitive pathway in the absence of Wnt3a. Lef/Tcf-sensitive transcriptional activation (the hallmark of activation of Wnt/beta-catenin pathway) and the assembly of Dvl3-based supermolecular complexes were followed and summarized in Table 2. The second approach to mimicking Wnt stimulation is the expression of constitutively active mutant (CA-delta-N) LRP6. Expression of the constitutively active mutant of LRP6 (CA-delta-N-LRP6) resulted in Wnt stimulation (Tamai et al., 2004). Mimicking Wnt3a action (in the absence of Wnt3a) by CAdelta-N-LRP6 was performed. Overexpression of CA-delta-N-LRP6 likewise provoked formation of the very large, supermolecular Dvl3-based complexes, just like Wnt3a itself (Table 2). Conversely, expression of the dominant-interfering delta-C-LRP6 blocked the canonical pathway and also abolished the formation of Dvl3-based supermolecular complexes. Inhibition of GSK3 $\beta$ activity is a third approach. The chemical inhibition of 
A

Blot:Dvl3

(-) Wnt3a

(t) Wnt $3 a, 30 \mathrm{~min}$

(+) Wnt 3a, $1 \mathrm{hr}$

(+) Wnt 3a, 2 hr

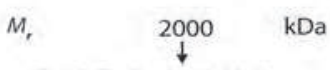
$\begin{array}{llllllll}18 & 20 & 22 & 24 & 26 & 30 & 34 & 38 \\ 16 & 19 & 21 & 23 & 25 & 28 & 32 & 36\end{array}$
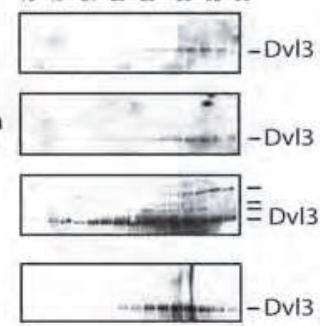

B

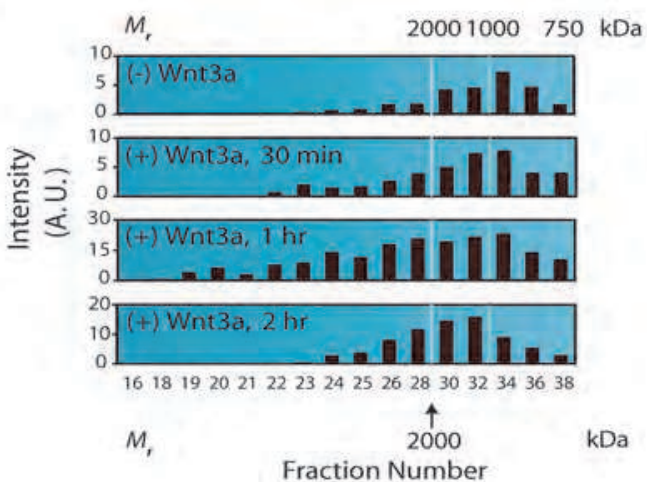

C Control

Dvl3 overexpression
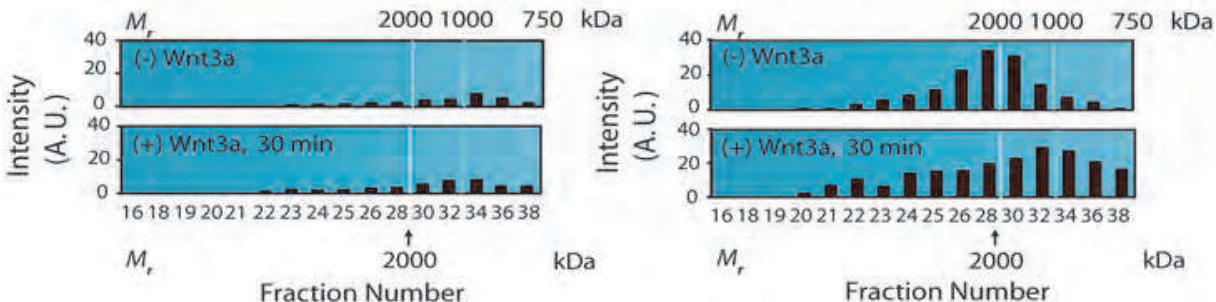

\section{Dvl1 overexpression}

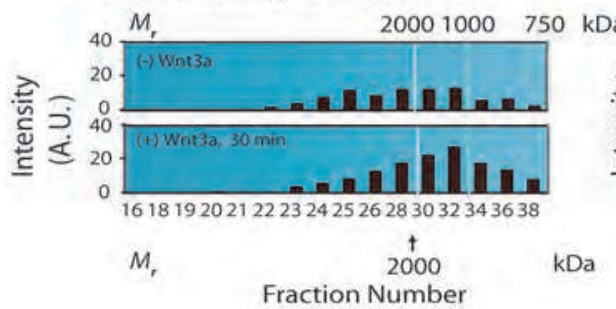

\section{Dvl2 overexpression}

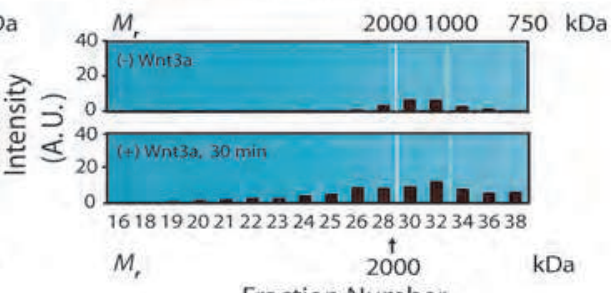

Fraction Number

(A, B) Dvl3 assembles supermolecular multi-protein complexes in response to Wnt3a, in a time-dependent manner. F9 cells were stimulated with Wnt3a for the indicated times. Cells were lysed and subject to stericexclusion chromatography on Superdex 200. Fractions were analyzed by SDS-PAGE and resolved proteins immunoblotted with isoform-specific Dvl antibodies. Dvl3 blot (A) and quantitative analysis of Dvl3 (B) in the region above $750 \mathrm{kDa}-M_{r}$.

(C) Overexpression of Dvls provoked formation of supermolecular Dvl3-based complexes without Wnt3a stimulation. F9 cells were co-transfected with Rfz1 and either GFP- and HA-tagged mouse Dvl1, or Dvl2 or Dvl3. F9 cells were either unstimulated or stimulated with Wnt3a for 30 minutes. Cells lysates were applied to Superdex 200 gel filtration column. Fractions were analyzed by SDS-PAGE. Resolved proteins were immunoblotted with anti-Dvl3 antibody and quantified. Data are adapted with permission from the publication (Yokoyama, N., Golebiewska, U., Wang, H. Y. \& Malbon, C. C. (2010) J Cell Sci 123, 3693-3702).

Fig. 7. Assembly of Dvl3-based supermolecular complexes by Wnt stimulation and overexpression of Dvls. 
GSK3 $\beta$ by LiCl stimulates Lef/Tcf-sensitive transcription (Stambolic et al., 1996). Inhibition of GSK3 $\beta$ provoked increased formation of the very large $\left(>2.0\right.$ MegaDa- $\left.M_{r}\right)$ Dvl3-based supermolecular complexes (Table 2).

To define precisely roles of Dvl isoforms on the assembly of Dvl3-based supermolecular complexes, the effect of knockdown of each Dvl isoform was investigated (Table 2). Knockdown of each Dvl isoform resulted in attenuation of the assembly of Dvl3-based supermolecular complexes as well as Lef/Tcf-sensitive transcription. Knockdown of Dvl1 and Dvl3, lower abundance of Dvls in F9 cells, was more effective on both parameters. Knockdown of Dvl3 essentially precluded formation of the supermolecular complex in the absence or presence of Wnt3a. Knockdown of Dvl1 had little effect on the abundance of the basal Dvl3-based complex (i.e., without Wnt3a stimulation), but attenuated Wnt3a provoked formation of Dvl3-based supermolecular complexes (>2.0 MegaDa- $\left.M_{r}\right)$. Knockdown of the most abundant isoform Dvl2 severely reduced the abundance of the Dvl3-based complexes in the absence of Wnt3a. Wnt3a failed to stimulate the formation of supermolecular Dvl3based complexes as well as activation of the canonical pathway. Thus, clearly Dvl1 and Dvl2 cooperate in catalyzing the formation of supermolecular, Dvl3-based complexes in either the absence or presence of Wnt3a. Finally, Dickkopf homologue 1 (DKK1), a well known Wnt antagonist (Nusse, 2001), blocked both activation of the Wnt canonical pathway and formation of very large, Dvl3-based supermolecular complexes (Table 2).

\begin{tabular}{|c|c|c|c|c|}
\hline & \multicolumn{2}{|c|}{$(-)$ Wnt3a } & \multicolumn{2}{c|}{$(+)$ Wnt3a } \\
Oligomerization & $\begin{array}{c}\text { Lef/Tcf } \\
\text { transcription }\end{array}$ & Oligomerization & $\begin{array}{c}\text { Lef/Tcf } \\
\text { transcription }\end{array}$ \\
\hline Control & - & - & + & + \\
\hline DKK1 & - & - & - & - \\
\hline $\begin{array}{c}\text { delta-N- } \\
\text { LRP6 }\end{array}$ & + & + & - & - \\
\hline $\begin{array}{c}\text { delta-C- } \\
\text { LRP6 }\end{array}$ & - & - & + & ++ \\
\hline LiCl & ++ & ++ & ++ & ++ \\
\hline Dvl1 OE & ++ & ++ & + & + \\
\hline Dvl2 OE & + & + & +++ & - \\
\hline Dvl3 OE & +++ & +++ & + & - \\
\hline Dvl1KD & + & - & - & - \\
\hline Dvl2 KD & \pm & - & - & + \\
\hline Dvl3 KD & - & - & + & + \\
\hline
\end{tabular}

OE: overexpression; KD: knockdown; Data are adapted with permission from the publication (Yokoyama, N., Golebiewska, U., Wang, H. Y. \& Malbon, C. C. (2010) J Cell Sci 123, 3693-3702).

Table 2. Summary of Wnt activation and formation of Dvl3-based supermolecular complexes.

Thus, through targeted activation and disruption of Wnt3a signaling, a linkage between the ability to form very large ( $>2.0$ MegaDa- $M_{r}$ ) Dvl3-based supermolecular complexes and the level of activation of Lef/Tcf-sensitive transcription (functional downstream signaling) was established. Unique rolls of Dvl3 in Wnt/ $\beta$-catenin signaling demonstrate Dvl isoforms are 
not redundant with respect to function. Several key Dvl-interacting proteins (e.g., Dvl1, Dvl2, Dvl3, GSK3 $\beta$ and Axin) were present in these very large, Dvl3-based supermolecular complexes. Manipulations that provoked the formation of these Dvl3-based complexes also provoked activation of the Wnt/beta-catenin canonical pathway. Mutations of Dvl2 that block punctae formation inhibit the canonical Wnt signaling (Schwarz-Romond et al., 2007a). Dvl2/3 mutants, that do not form punctae, failed to assemble Dvl3-based supermolecular complexes (unpublished data). Phosphorylation-defective mutant of Dvl3 abolished assembly of Dvl3-based supermolecular complexes as well as activation of Wnt/beta-catenin signaling. On the other hand, Phosphorylation-mimetic mutant provoked both assembly of Dvl3-based supermolecular complexes and Lef/Tcf-sensitive transcription (unpublished data). The phosphorylation site was identified by CK1 $\delta$ in vitro followed by proteomics. Data established that phosphorylation of Dvls is a crucial regulatory mechanism for the spatial/temporal assembly of dynamic supermolecular complexes to transduce Wnt signaling. Recent report provided compelling evidence that phosphorylation by $\mathrm{CK} 1 \delta / \varepsilon$ sequentially regulates activation and de-activation of Dvls. Phosphorylated Dvls stimulate the oligomerization of Dvls, whereas the hyper-phosphorylated Dvls have less ability to oligomerize also form punctae (Bernatik et al., 2011).

\subsubsection{Analysis of Dvl3-based supermolecular complexes by fluorescence correlation spectroscopy (fcs)}

Fluorescence correlation spectroscopy $\left(f_{c s}\right)$ is used to probe the apparent size of the Dvl3and Dvl2-based complexes in F9 cell. Fcs measurements were performed on a Zeiss LSM 510 Meta/Confocor 2 apparatus (Jena, Germany) fitted with a $40 \times$ NA 1.2 C-Apochromat water immersion objective. Fcs of eGFP-tagged Dvl3 or Dvl2 in F9 cells was performed. In live cells the MW of Dvl3- and Dvl2-based supermolecular complexes was calculated. eGFP-tagged Dvl3 was tracked and the molecular weight calculated from the diffusion coefficients (Hess et al., 2002; Lakowicz, 2006; Schwille et al., 1999, Yokoyama et al., 2010). Two populations of eGFP-Dvl3 in unstimulated cells were obtained (Dvl3 dimers, i.e. $\sim 132 \mathrm{kDa}$, and very large oligomers of $\sim 35 \mathrm{MegaDa}$ ). Wnt stimulation slowed down the diffusion of the large complexes and increased the molecular mass of Dvl3-based complexes to $\sim 40 \mathrm{MegaDa}$. The diffusion of the smaller complexes did not change in response to Wnt treatment. By sharp contrast, Dvl2-based complexes did not change molecular mass before and after stimulation with Wnt3a. This phenomenon is coinciding with those obtained by SEC. Wnt treatment resulted in increase of the mass of Dvl3-based supermolecular complexes, similar to those by SEC. The MW determined by $f(S$ is much larger than that reported on the bases of SEC analysis with a Sephacryl S-400 column (HiPrep Sephacryl S400 high-resolution column 16/ 60, fast-performance AKTA liquid chromatography) (3-7 MegaDa- $M_{r}$ ). The size of Dvl3based supermolecular complexes by SEC is reassessed and amended to $35 \mathrm{MegaDa}$, similar to those identified by $f c s$ (Patel \& Winzor., 2010).

\subsubsection{Proteomic analysis of Dvl3-based supermolecular complexes in response to Wnt3a}

Thus the assembly of Dvl3-based supermolecular complexes in response to Wnt stimulation is established. Next important questions are "What are the compositions in Dvl3-based supermolecular complexes?" and "How is assembly/disassembly of Dvl3-based complexes regulated?" Proteomic analysis was employed to dissect the compositions of supermolecular 
Dvl3-based complexes. Over 3 MegaDa- $M_{r}$ peak fractions of Dvl3-based supermolecular complexes separated by SEC from Wnt3a treated or untreated cells were subjected to LCESI-MS-MS. Dvl3-based supermolecular complexes ( $>3$ MegaDa- $M_{r}$ ) isolated by SEC are distributed in a less populated region of the chromatogram (i.e., near void volume). Limited amount of proteins ( $\sim 1 \%$ of total proteins) migrate to $>3$ MegaDa- $M_{r}$ peak without Wnt stimulation. Wnt stimulation enhanced the abundance of these proteins 2-4 times in $>3$ MegaDa- $M_{r}$ region. The low amount of proteins in $>3$ MegaDa- $M_{r}$ region allowed executing proteomic analysis, although a main concerning of this application is potential contamination of proteins/complexes of $M_{r}$ similar to that of the Dvl3-based supermolecular complexes. However, unrelated proteins/complexes (contamination) would not co-migrate with the Dvl3-based supermolecular complexes and also would not response to Wnt stimulation.

To minimize potential contamination, the analysis was carried out at distinct time points $(0$, 5,10 and $30 \mathrm{~min}$ ). By comparing the proteomic profiles from $>3 \mathrm{MegaDa}-M_{r}$ complexes with Wnt stimulation versus without Wnt stimulation, it will be possible to define the relative abundance of partners in $>3$ MegaDa- $M_{r}$ peak in a Wnt- and time-dependent manner.

\subsubsection{Proteomics of Dvl3-based supermolecular complexes}

Pooled peaks (over 3 MegaDa- $M_{r}$ ) were subjected to TCA precipitation. Protein TCA pellets were resuspended in $10 \mu \mathrm{l}$ of $8 \mathrm{M}$ urea, and diluted to $2 \mathrm{M}$ urea with $0.1 \mathrm{M}$ ammonium bicarbonate. The proteins were reduced with $5 \mathrm{mM}$ DTT and alkylated with $10 \mathrm{mM}$ iodoacetamide. $2 \mu \mathrm{g}$ of trypsin was added to the proteins and incubated overnight at $37{ }^{\circ} \mathrm{C}$. The digestion reaction was stopped with formic acid (5\% final concentration).

Multidimensional chromatography was applied. Peptide mixtures were pressure-loaded onto a $250 \mu \mathrm{m}$ inner diameter (i.d.) fused-silica capillary packed first with $3 \mathrm{~cm}$ of $5 \mu \mathrm{m}$ strong cation exchange material (Partisphere SCX, Whatman), followed by $3 \mathrm{~cm}$ of $10 \mu \mathrm{m}$ C18 reverse phase (RP) particles (Magic, Michrom). Loaded and washed microcapillaries were connected to a $100 \mu \mathrm{m}$ i.d. column, which had been pulled to a $5 \mu \mathrm{m}$ i.d. tip using a P-2000 $\mathrm{CO}_{2}$ laser puller (Sutter Instruments), then packed with $13 \mathrm{~cm}$ of $3 \mu \mathrm{m} \mathrm{C} 18$ reverse phase (RP) particles (Magic, Michrom) and equilibrated in $2 \%$ acetonitrile, $0.1 \%$ formic acid (Buffer A). This split-column was then installed in-line with Thermo Surveyor MS HPLC pump. The flow rate was $\sim 500 \mathrm{nl} / \mathrm{min}$. Fully automated 12-step chromatography runs were carried out. Three different elution buffers were used: $2 \%$ acetonitrile, $0.1 \%$ formic acid (Buffer A); $98 \%$ acetonitrile, $0.1 \%$ formic acid (Buffer B); and $0.5 \mathrm{M}$ ammonium acetate, $2 \%$ acetonitrile, $0.1 \%$ formic acid (Buffer C). In such sequences of chromatographic events, peptides were sequentially eluted from the SCX resin to the RP resin by increasing salt steps (increase in Buffer $C$ concentration), followed by organic gradients (increase in Buffer B concentration). The last chromatography step consisted in a high salt wash with $100 \%$ Buffer C followed by acetonitrile gradient. The application of a $1.8 \mathrm{kV}$ distal voltage electrosprayed the eluting peptides directly into a LTQ mass spectrometer equipped with a nano-LC electrospray ionization source. Full MS spectra were recorded on the peptides over a 400 to $2000 \mathrm{~m} / \mathrm{z}$ range, followed by five tandem mass (MS/MS) events sequentially generated in a data-dependent manner on the first, second, third, fourth, fifth most intense ions selected from the full MS spectrum (at 35\% collision energy). Mass spectrometer scan functions and HPLC solvent gradients were controlled by the Xcalibur data system (ThermoFinnigan). 
Tandem mass spectra were extracted by RawXtract version 1.9.7. All MS/MS samples were analyzed using Sequest (Thermo Fisher Scientific). Sequest was set up to search a mouse IPI database (ver. 3.75), including reversed sequences (in total 113990 entries) assuming no specific protease. Sequest was searched with a parent ion tolerance of 1.5Da. Iodoacetamide derivative of cysteine was specified in Sequest as a fixed modification.

Scaffold (version Scaffold_3_00_08, Proteome Software Inc.) was used to validate MS/MS based peptide and protein identifications. Peptide identifications were accepted if they could be established at greater than $95.0 \%$ probability as specified by the Peptide Prophet algorithm (Keller et al., 2002). Protein identifications were accepted if they could be established at greater than $99.0 \%$ probability and contained at least 2 identified peptides. Protein probabilities were assigned by the Protein Prophet algorithm (Nesvizhskii et al., 2003). Proteins that contained similar peptides and could not be differentiated based on MS/MS analysis alone were grouped to satisfy the principles of parsimony.

\subsubsection{Evaluation of compositions of Dvl3-based supermolecular complexes in response to Wnt3a}

Data were normalized between distinct time points and positive identification was ascribed to a protein which had at least 30 unique fragments. Proteins, which abundance was changed during Wnt stimulation, were further analyzed. This strategy may identify other supermolecular complexes occurred in advance of Wnt signaling as well. Analysis of proteomics identified both expected and also novel components. Identified compositions of Dvl3-based complexes included protein kinases and phosphatases (serine/threonine and tyrosine), guanine nucleotide binding proteins, inositol phosphate related proteins, Wnt signaling related proteins and other signaling molecules.

Detected known Dvls interacting proteins are listed in Table 3. Presence of Dvls interacting proteins (17 distinct proteins) in the above $\sim 3 \mathrm{MegaDa}-M_{r}$ region strongly indicated these proteins may assemble with Dvl3-based supermolecular complexes.

\begin{tabular}{|l|l|}
\hline \multicolumn{2}{|c|}{ Identified known Dvls interacting proteins } \\
\hline PI4kinase & Ephrin B1 \\
\hline CK1 $\gamma$ & aPKC \\
\hline Src & Par1 \\
\hline PTK7 & Calpain \\
\hline AP-2 & Daam 1 \\
\hline Actin & CK1 $\alpha$ \\
\hline LRP6 & CK2 $\alpha$ \\
\hline PP2A & CK2 $\beta$ \\
\hline Ror2 & \\
\hline
\end{tabular}

Table 3. Identified known Dvls interaction proteins.

Identified key molecules involving in Wnt signaling pathway include Rho, G $\alpha$ family, G $\beta 1$ and $\mathrm{mTOR}$, and abundance of these proteins was changed after Wnt stimulation (Table 4). Data represent the diversities and complexities of Wnt signaling pathways which Dvls are involved in. Proteomic analysis identified proteins related in the Wnt/ $\beta$-catenin signaling pathway, but also proteins involved in the planar cell polarity $(\mathrm{PCP})$ pathway, Wnt/ $\mathrm{Ca}^{2+}$ pathway and other signaling pathway. 


\begin{tabular}{|c|c|}
\hline \multicolumn{2}{|c|}{ Wnt signaling related proteins } \\
\hline Rho GTPase 2 & mTOR \\
\hline Gai2 & Gai3 \\
\hline Gas & Gß1 \\
\hline Ga13 & \\
\hline
\end{tabular}

Table 4. Identified Wnt signaling related proteins.

Many proteins such as PI4 kinase, CK1 $\gamma$, Src, LRP6, PP2A, Par1, CK1 $\alpha$, CK2 $\alpha$ and CK2 $\beta$ are important key molecules in Wnt/ $\beta$-catenin signaling pathway and are already known Dvl interacting proteins. Wnt treatment quickly produces plasma-membrane-associated LRP6 aggregates (Bilic et al., 2007). CK1 $\gamma$ phosphorylates LRP5/6 in response to Wnt3a (Davidson et al., 2005). Phosphorylation of LRP5/6 promotes Axin recruitment (Davidson et al., 2005; Tolwinski et al., 2003; Zeng et al., 2005). PI4 kinase together with PI5K kinase enhances PIP2 production and stimulates clustering of Dvls and LRP5/ 6 receptor (Pan et al., 2008). To see whether key parameters in the Dvl3-based supermolecular complexes will change in response to Wnt stimulation, tentative analysis of these parameters was carried out, although these data are not precisely quantitative (fig. 8A and 8B). First key step after Wnt stimulation is the phosphorylation of LRP6 by CK1 $\gamma$. The abundance of LRP in the Dvl3based supermolecular complexes was increased two times 5 min post stimulation by Wnt3a and sustained over $30 \mathrm{~min}$. The abundance of CK1 $\gamma$ in the Dvl3-based supermolecular complexes was increased $5 \mathrm{~min}$ post Wnt stimulation and peaked at $10 \mathrm{~min}$ thereafter decreased (fig. 8A). Thus, similar migration of two components was obtained in response to Wnt3a. These time courses fit quite well to a previous report, which demonstrated that LRP6 starts coalescing into punctate structures at or below the plasma membrane within $15 \mathrm{~min}$ Wnt stimulation. PI4 kinase, which is involved in the production of PtdIns $(4,5) \mathrm{P}_{2}$, dramatically increased $10 \mathrm{~min}$ post Wnt stimulation (fig. 8A). Data fits well with a previous report that significant PtdIns $(4,5) \mathrm{P}_{2}$ formation was detected $15-30 \mathrm{~min}$ after Wnt3a stimulation (Pan et al., 2008). In contrast, proteins like actin did not change significantly upon Wnt stimulation. Many Dvls interacting proteins, which are involved in the Wnt/ $\beta$ catenin signaling, CK1 $\alpha, \mathrm{CK} 2 \alpha, \mathrm{CK} 1 \gamma$, PI4kinaae and Src migrated at $>3$ MegaDa- $M_{r}$ region after 5-10min Wnt stimulation (fig. 8B). Previous data showed that Src docking to Dvl2 is increased after 5-10min Wnt stimulation and sustained for 45min (Yokoyama and Malbon, 2007). Changing of Src abundance in the Dvl3-based supermolecular complexes was matched to the previous finding. Furthermore, not all proteins found in $>3$ MegaDa- $M_{r}$ region were increased during Wnt stimulation. Migration of Par1 was decreased upon Wnt stimulation (fig. 8B). Also proteins such as tubulin, HSP60 and 40S ribosomal protein in $>3$ MegaDa- $M_{r}$ region were decreased upon Wnt stimulation. Together, migrations of proteins found in the Dvl3-based supermolecular complexes were responsive to Wnt stimulation temporally and some of them were correlated well, suggesting that results obtained by proteomic analysis represent proper variations of compositions.

Interesting observations are several proteins involved in the PCP pathway, Daam 1, PTK7, AP2, Par1, Ephrin B1 and Rho GTPase, were also found in $>3$ MegaDa- $M_{r}$ peak. Therefore, whether or not activation of PCP pathway would provoke assembly of Dvl3-based supermolecular complexes was investigated. Wnt5a has been classified as a non-canonical Wnt family member. Rat Fz2 (Rfz2) expressing F9 cells were stimulated with Wnt5a for 30 min and cell lysates were separated by SEC and further analyzed by immunoblotting with anti-Dvl3 
A

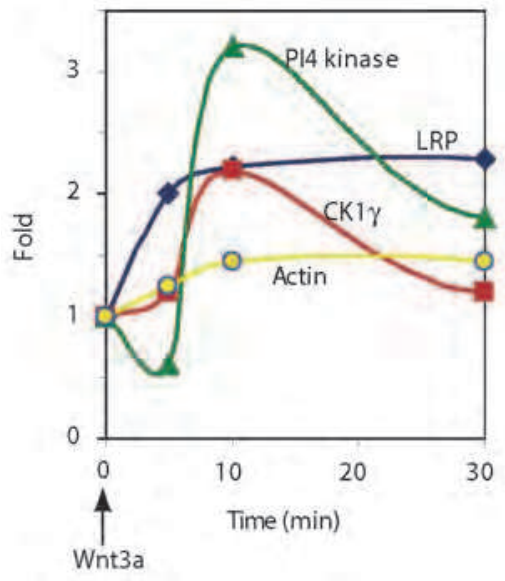

B

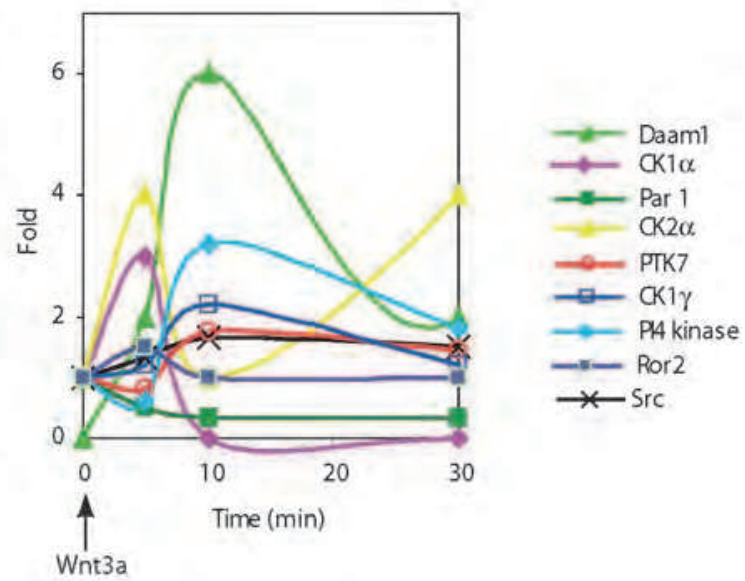

(A) Time courses of LRP, CK1 $\gamma$ and PI4K in $>3$ MegaDa- $M_{r}$ peak. Changes of LRP, CK1 $\gamma$, PI4K and actin in response to Wnt3a stimulation are displayed.

(B) Wnt3a responsive Dvls interacting proteins in $>3$ MegaDa- $M_{r}$ peak are displayed.

Fig. 8. Time courses of key components presented in >3 MegaDa- $M_{r}$.

antibody. Indeed, assembly of Dvl3-based supermolecular complexes was detected in Rfz2 expressing F9 cell in response to Wnt5a, demonstrating Wnt5a-dependent assembly of the large complexes is provoked in the PCP pathway as well (fig. 9). PCP signaling is pivotal for establishing cell polarity and activation of PCP pathway leads to the activation of Rhofamily GTPase and JNK through Dvls and Dishevelled-associated activator of morphogenesis 1 (Daam1) (Wallingford and Habas, 2005). Daam 1 bound to both Rho GTPase and Dvl, mediates Wnt-induced Dvl/Rho complex formation, which in turn activates Rho-associated protein kinase (ROCK) and remodels cytoskeleton (Habas et al., 2001). Daam1 is imprecated in cancer through its regulation of endocytosis of Ephrin B1 (Kida et al., 2007). Furthermore, proteomics also identified Ror2, which is involved in Wnt/ $\mathrm{Ca}^{2+}$ pathway. Ror2 is a receptor tyrosine kinase. Wnt interaction with $\mathrm{Fz}$ and coreceptor Kyn or Ror2 provokes increase of intracellular $\mathrm{Ca}^{2+}$ level and subsequently activates calcium/calmodulin-dependent protein kinase II (CaMKII), protein kinase C (PKC) and nuclear factor of activated T cells (NFAT). $\mathrm{Ca}^{2+}$ is a central regulator of many cell functions and its downstream targets are numerous. Ror2 also shown as a receptor for Wnt5a, stimulating the non-canonical pathway (Oishi et al., 2003). In addition, Ror2 has a opposing role in the canonical signaling pathway and is able to inhibit Wnt/ $\beta$-catenin signaling (Mikels and Nusse, 2006). Tyrosine kinase activity of Ror2 is indispensable for Wnt5ainduced inhibition of Wnt/ $\beta$-catenin signaling (Mikels et al., 2009). Direct interaction of Ror2 with phosphorylated Dvl is required for the inhibition of Wnt/ $\beta$-catenin signaling (Witte et al., 2010). Thus, Ror2 plays diverse roles in the discrete Wnt signaling pathways. 
$\mathrm{Fz1}$

$(-)$ Wnt3a

Blot: Dvl3

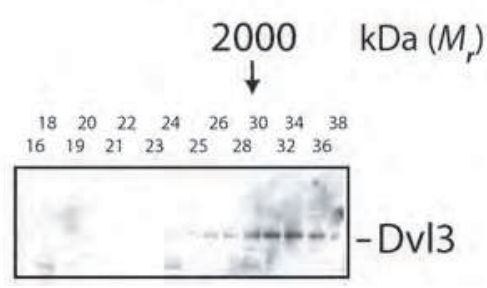

(-) Wnt5a

$\mathrm{Fz2}$

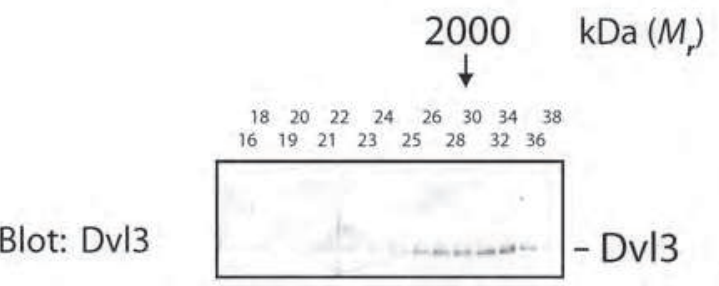

(+) Wnt3a, $30 \mathrm{~min}$

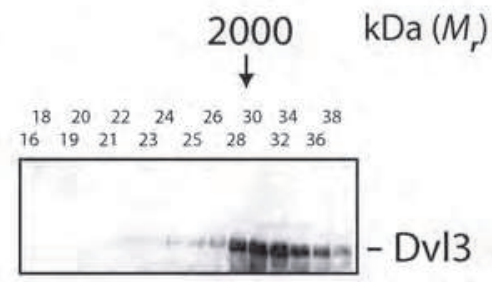

(+) Wnt5a, $30 \mathrm{~min}$

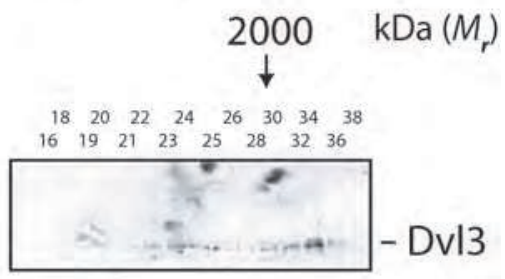

F9 cells expressing either Rfz1 or Rfz2 were stimulated with Wnt3a or Wnt5a for 30min, respectively. Cell lysates were subjected to the gel filtration chromatography and then fractions were analyzed by SDS-PAGE and blotted with anti-Dvl3 antibody. The regions above $750 \mathrm{kDa}-M_{r}$ were shown.

Fig. 9. Dvl3-based supermolecular complexes are assembled in the PCP pathway.

Similarly, Par1 is discovered as a Dsh-associated kinase in Drosophila (Sun et al., 2001) and an essential for canonical signaling pathway, but also functions in non-canonical pathway (Wharton, 2003). Thus, certain molecules are involved in several distinct pathways. Presence of mammalian target of rapamycin (mTOR) in the $>3$ MegaDa- $M_{r}$ region also demonstrates diversity of Wnt signaling pathways (Table 4), and supporting a previous finding that Wntmediated signaling activates mTOR mediated translational regulation in tumorigenesis (Inoki et al., 2006). Wnt activates mTOR via inhibiting GSK3 (Inoki et al., 2006) and the phosphorylation of tuberous sclerosis complex 2 (TSC2), a tumor-suppressor which negatively regulates mTOR, is suppressed (Mak et al., 2005). These data suggesting that Wnt signaling pathway is integrated to control mTOR activity (Choo et al., 2006).

$G$ proteins found in the Dvl3-based supermolecular complexes are reasonable and expected

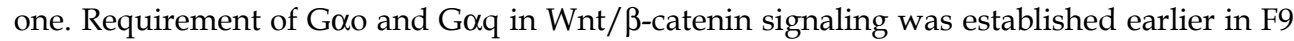
cell (Liu et al., 1999). G $\alpha 13$, essential for the formation of the primitive endoderm, induces the activation of Rho protein, mitogen-activated protein kinase kinase (MEKK) and Jun-Nterminal kinase-1 (JNK1) in P19 embryonal carcinoma cells (Jho and Malbon, 1997; Lee et al., 2004). Go13and Goi family functions in development and deficiency of these G proteins causes embryonic lethality (Offermanns et al., 1997; Wettschureck et al., 2004). Novel classes of signaling proteins found in this large $M_{r}$ peak included cAMP-dependent protein kinase, cell division protein kinase, Yes, Fyn, serine/threonine and tyrosine protein phosphatases, inositol 1, 4, 5-triphosphate receptor, phosphoinositide 3-kinase, phosphatidylinositol-4- 
phosphate 3-kinase, AKAP 1 and 14-3-3. Many proteolytic targeting proteins including E3 ubiquitin-protein ligase NEDD4, Cullin 4B etc. were also found in $>3$ MegaDa- $M_{r}$ peak, suggesting an important implication for Wnt-initiated tumorigenesis. Functional analysis demonstrated that Dvls stability is regulated by Cullin 3 ubiquitin ligase complex containing KLH12 (Angers et al., 2006). Some of them were identified by two distinct approaches (GST fusion pulls down and application of proteomics to Dvl3-based supermolecular complexes). Overall, the combined approaches of SEC and proteomics are successful to dissect Dvl3based supermolecular complexes. Key Dvls interacting proteins, known functions in Wnt/beta-catenin signaling, present in $>3$ MegaDa- $M_{r}$ peak, suggesting a compelling evidence that these proteins form complexes with Dvl3. Dvl3-based supermolecular complexes assemble at early stage and their compositions are dynamically changed during Wnt stimulation. Data agrees well with the fact that the size and localization of Dishevelled-based "punctae" have been changed upon Wnt stimulation observed earlier by fluorescence microscopy. Further segregation of unrelated proteins from the enriched Dvl3-based complexes, if possible, will be a benefit to analyze dynamic assembly of molecules central to the function of the Wnt/ beta-catenin canonical signaling.

There are at least three major Wnt signaling branches, Wnt/ $\beta$-catenin (canonical) pathway, PCP pathway (non-canonical) and Wnt/ $\mathrm{Ca}^{2+}$ pathway. Proteomics in the $>3$ MegaDa- $M_{r}$ region have identified proteins, which are involved in Wnt/ $\beta$-catenin signaling pathway as well as the PCP and $\mathrm{Wnt} / \mathrm{Ca}^{2+}$ pathways, suggest that these pathways may share a large signaling network. Wnt signaling pathways may not tightly isolate or share intracellular components between pathways. In this way, Wnt signaling pathways can cross talk with each other or other signaling pathways. Accumulated evidences show the cross talk between distinct Wnt pathways as well as other signaling pathways. Diversities of Wnt ligands and its receptors contribute to the complexities of Wnt signaling pathways. Distinct Wnt ligands can initiate discrete signaling pathways through its distinct receptors; however, signaling by different Wnt family members is not only intrinsically regulated by the Wnt proteins themselves, but also by receptor availability (cellular context of the receptor). Some Wnt ligand can bind to non-Frizzled receptor like Ror2 or RYK (an atypical Tyrosine kinase receptor) etc. RYK lacks a functional tyrosine kinase domain, but contains a module homologous to the Wnt-binding domain (Lu et al., 2004). Moreover, same Wnt ligand stimulates or inhibits distinct Wnt signaling pathways through its distinct receptors. Certain Wnt ligand activates the PCP and Wnt/ $\mathrm{Ca}^{2+}$ pathways. Our SEC data demonstrate that Dvl3-based supermolecular complexes $\left(\sim 2\right.$ MegaDa- $\left.M_{r}\right)$ are assembling at the basal level (i.e., without Wnt stimulation) and Wnt stimulation provokes the upshift of molecular mass of Dvl3-based mutiprotein complexes. Data may suggest that without Wnt stimulation, Wnt signaling pathways may share fundamental platform of Dvls-based complexes, because Dvls are essential scaffold components in all three branches and transduce signals to distinct downstream pathways. In one way, we could say that distinct Wnt ligands provoke assembly of distinct multiprotein complexes. However, more detailed knowledge of the specificity of Wnt ligand and receptor, the receptor availability and protein components mediating signals to downstream are required to answer "How Dvls transduce signals to distinct Wnt signaling pathways?" and "How Wnt signaling integrates with other signaling pathways to form signaling network?" Dvls are a major player in Wnt signaling pathways and scaffold multiproteins to form the platform. Therefore, more precise analysis of protein compositions in the supermolecular complexes, not only Wnt/ $\beta$ - 
catenin signaling pathway as well as PCP pathway and $\mathrm{Wnt} / \mathrm{Ca}^{2+}$ pathway, is required. Our data demonstrate that the assembly of Dvl3-based supermolecular complexes is provoked in the PCP pathway. Similar to the Wnt/ $\beta$-catenin signaling, the molecular mass of Dvl3-based supermolecular complexes is upshifted in the response to Wnt5a. There is no information whether Dvls-based supermolecular complexes form in Wnt/ $\mathrm{Ca}^{2+}$ signaling pathway. Comparison of proteomic profiles of Dvl3-based supermolecular complexes in the $\mathrm{Wnt} / \beta$-catenin signaling versus the PCP pathway may provide a clearer image of signaling specific compositions of the supermolecular complexes. Precise regulations of Wnt signaling pathway by the Dvls-based supermolecular complexes are needed to analyze more widely in all branches. Advanced proteomic analysis of the Dvlsbased supermolecular complexes with high-throughput screening offers an ideal strategy to interrogate the composition of Dvl3-based supermolecular complexes in the Wnt/ $\beta$ catenin signaling pathway as well as in the non-canonical signaling pathway.

\section{Conclusion}

Dvls are scaffold proteins and Wnt signaling is transduced through the dynamic assembly/disassembly of protein complexes with Dvls called "signalsomes". Dvls-based supermolecular complexes provide a platform for recruiting many docking proteins and organizing dynamic assembly of proteins. Dvls-based punctae have been visualized by fluorescence microscopy and displayed dynamic protein assemblies. Proteomics of immobilized GST-domain pull down identified several novel and functional Dvl2 interacting proteins. Novel positive roles for Src family tyrosine kinases in Wnt/ $\beta$-catenin signaling also have been established by GST-domain pull down and proteomics. Identification of tyrosine phosphorylation sites on Dvl2 leads to the discovery of the positive role of Src family kinases in Wnt/ $\beta$-catenin signaling. Wnt stimulates Src docking to Dvl2 and activates Src tyrosine kinase. Activated Src enhances Wnt activation of the canonical pathway via phosphorylation of Dvl2 and $\beta$-catenin.

The physical nature and the dynamic character of the Dvl3-based supermolecular complexes have been established first time. The formation of these very large, supermolecular Dvl3based complexes in response to Wnt3a is found to be a time-dependent manner and dynamic in character. The assembly of Dvl3-based supermolecular complexes ( $>3$ MegaDa$M_{r}$ ) occurred at very early stage (detected as early as $5 \mathrm{~min}$ post-Wnt3a stimulation) and maximized 30-60 min post-Wnt stimulation, in advances of the Lef/Tcf sensitivetranscription. Formation of very large Dvl3-based supermolecular complexes is essential in Wnt canonical signaling. Data demonstrate "punctae", Lef/Tcf-sensitive transcription (hallmark of activation of Wnt/beta catenin pathway) and dynamically assembled Dvl3based supermolecular complexes are functionally obligate to Wnt signaling. The mass of very huge Dvl3-based supermolecular complexes reveals MW ranging from 25-35 MegaDa by $f c s$. Reassessed size of Dvl3-based supermolecular complexes is $35 \mathrm{MegaDa}$ by SEC, similar to those obtained by $f c s$. This study demonstrates successful probing of signalsomes by SEC, $f c s$, affinity pull down and advanced proteomics.

Application of the proteomics in Dvl3-based supermolecular complexes provides physical properties of the assemblies. This approach is still experimental and challenging efforts, because cardinal concern is that Dvl3-based supermolecular complexes separated by SEC may contain unrelated proteins. Unsuccessful further separation of pure Dvl3-based supermolecular complexes is the barrier of this approach, because the size of the very huge 
Dvl3-based complexes interfered with further purification. Immunoprecipitation might be a useful approach, although there are difficulties to precipitate very large complexes, because epitope sites in the supermolecular complexes are not fully exposed. Under these circumstances, employed proteomics in the Dvl3-based supermolecular complexes provide invaluable information to address "What are the compositions of Dvl3-based supermolecular complexes?" and "How is the assembly/disassembly of Dvl3-based complexes temporally and spatially regulated?" More detailed analysis of the Dvls-based supermolecular complexes in all three Wnt signaling pathways is necessary. Thus, compelling, albeit indirect, studies established the natures of Dvl3-based supermolecular complexes by advanced proteomics. Novel proteins found in Dvl3-based supermolecular complexes need to be validated with functional analysis in vivo and in vitro.

\section{Acknowledgements}

The author thanks Dr. Craig. C. Malbon (Department of Pharmacology, School of Medicine, Health Sciences Center, State University of New York at Stony Brook) for helpful discussions and support. The author thanks the staff of the Proteomics Center (State University of New York at Stony Brook) for mass spectrometry analysis. The author acknowledges the contribution of Dr. Weiping Xie (present address: Pioneer Hi-Bred International DuPont Agricultural Biotechnology) in the first half of proteomics work. The author also thanks Drs. Antonius Koller and Emily Chen for technical support in the proteomic analysis. The author acknowledges the contribution of Drs. Urszula Golebiewska and Hsien-yu Wang (Department of Physiology and Biophysics, School of Medicine, Health Sciences Center, State University of New York at Stony Brook) for fcs analysis.

\section{References}

Angers S \& Moon RT. (2009). Proximal events in Wht signal transduction. Nat Rev Mol Cell Biol 10:468-477.

Angers S, Thorpe CJ, Biechele TL, Goldenberg SJ, Zheng N, MacCoss MJ \& Moon RT. (2006). The KLHL12-Cullin-3 ubiquitin ligase negatively regulates the Wnt-beta-catenin pathway by targeting Dishevelled for degradation. Nat Cell Biol 8:348-357.

Axelrod JD, Miller JR, Shulman JM, Moon RT \& Perrimon N. (1998). Differential recruitment of Dishevelled provides signaling specificity in the planar cell polarity and Wingless signaling pathways. Genes Dev 12:2610-2622.

Bernatik O, Ganji RS, Dijksterhuis JP, Konik P, Cervenka I, Polonio T, Krejci P, Schulte G \& Bryja V. (2011). Sequential activation and inactivation of Dishevelled in the Wnt/betacatenin pathway by casein kinases. J Biol Chem 286:10396-10410.

Bilic J, Huang YL, Davidson G, Zimmermann T, Cruciat CM, Bienz M \& Niehrs C. (2007). Wht induces LRP6 signalosomes and promotes dishevelled-dependent LRP6 phosphorylation. Science 316:1619-1622.

Brown MT \& Cooper JA. (1996). Regulation, substrates and functions of src. Biochim Biophys Acta 1287:121-149. 
Cervenka I, Wolf J, Masek J, Krejci P, Wilcox WR, Kozubik A, Schulte G, Gutkind JS \& Bryja V. (2011). Mitogen-activated protein kinases promote WNT/beta-catenin signaling via phosphorylation of LRP6. Mol Cell Biol 31:179-189.

Choo AY, Roux PP \& Blenis J. (2006). Mind the GAP: Wnt steps onto the mTORC1 train. Cell 126:834-836.

Clevers H. (2006). Wnt/beta-Catenin Signaling in Development and Disease. Cell 127:469-480.

Coluccia AM, Vacca A, Dunach M, Mologni L, Redaelli S, Bustos VH, Benati D, Pinna LA \& Gambacorti-Passerini C. (2007). Bcr-Abl stabilizes beta-catenin in chronic myeloid leukemia through its tyrosine phosphorylation. Embo J 26:1456-1466.

Cong F, Schweizer L \& Varmus H. (2004). Casein kinase Iepsilon modulates the signaling specificities of dishevelled. Mol Cell Biol 24:2000-2011.

Davidson G, Wu W, Shen J, Bilic J, Fenger U, Stannek P, Glinka A \& Niehrs C. (2005). Casein kinase 1 gamma couples Wnt receptor activation to cytoplasmic signal transduction. Nature 438:867-872.

Etheridge SL, Ray S, Li S, Hamblet NS, Lijam N, Tsang M, Greer J, Kardos N, Wang J, Sussman DJ, Chen P \& Wynshaw-Boris A. (2008). Murine dishevelled 3 functions in redundant pathways with dishevelled 1 and 2 in normal cardiac outflow tract, cochlea, and neural tube development. PLoS Genet 4:e1000259.

Glass DA, 2nd \& Karsenty G. (2006). Molecular bases of the regulation of bone remodeling by the canonical Wnt signaling pathway. Curr Top Dev Biol 73:43-84.

Habas R, Kato Y \& He X. (2001). Wnt/Frizzled activation of Rho regulates vertebrate gastrulation and requires a novel Formin homology protein Daam1. Cell 107:843-854.

Habedanck R, Stierhof YD, Wilkinson CJ \& Nigg EA. (2005). The Polo kinase Plk4 functions in centriole duplication. Nat Cell Biol 7:1140-1146.

Hamblet NS, Lijam N, Ruiz-Lozano P, Wang J, Yang Y, Luo Z, Mei L, Chien KR, Sussman DJ \& Wynshaw-Boris A. (2002). Dishevelled 2 is essential for cardiac outflow tract development, somite segmentation and neural tube closure. Development 129: 58275838 .

He X, Semenov M, Tamai K \& Zeng X. (2004). LDL receptor-related proteins 5 and 6 in Wnt/beta-catenin signaling: arrows point the way. Development 131:1663-1677.

Hendriks WJ, Dilaver G, Noordman YE, Kremer B \& Fransen JA. (2009). PTPRR protein tyrosine phosphatase isoforms and locomotion of vesicles and mice. Cerebellum 8:80-88.

Hess ST, Huang S, Heikal AA \& Webb WW. (2002). Biological and chemical applications of fluorescence correlation spectroscopy: a review. Biochemistry 41:697-705.

Inoki K, Ouyang H, Zhu T, Lindvall C, Wang Y, Zhang X, Yang Q, Bennett C, Harada Y, Stankunas K, Wang CY, He X, MacDougald OA, You M, Williams BO \& Guan KL. (2006). TSC2 integrates Wht and energy signals via a coordinated phosphorylation by AMPK and GSK3 to regulate cell growth. Cell 126:955-968.

Jho EH \& Malbon CC. (1997). Galpha12 and Galpha13 mediate differentiation of P19 mouse embryonal carcinoma cells in response to retinoic acid. J Biol Chem 272:24461-24467.

Karni R, Gus Y, Dor Y, Meyuhas O \& Levitzki A. (2005). Active Src elevates the expression of beta-catenin by enhancement of cap-dependent translation. Mol Cell Biol 25:5031-5039.

Katanaev VL, Ponzielli R, Semeriva M \& Tomlinson A. (2005). Trimeric G protein-dependent frizzled signaling in Drosophila. Cell 120:111-122. 
Keller RA, Ambrose WP, Arias AA, Cai H, Emory SR, Goodwin PM \& Jett JH. (2002). Analytical applications of single-molecule detection. Anal Chem 74:316A-324A.

Kida YS, Sato T, Miyasaka KY, Suto A \& Ogura T. (2007). Daam1 regulates the endocytosis of EphB during the convergent extension of the zebrafish notochord. Proc Natl Acad Sci U S A 104:6708-6713

Kishida M, Hino S, Michiue T, Yamamoto H, Kishida S, Fukui A, Asashima M \& Kikuchi A. (2001). Synergistic activation of the Wnt signaling pathway by Dol and casein kinase Iepsilon. J Biol Chem 276:33147-33155.

Kishida S, Yamamoto H, Hino S, Ikeda S, Kishida M \& Kikuchi A. (1999). DIX domains of Dvl and axin are necessary for protein interactions and their ability to regulate beta-catenin stability. Mol Cell Biol 19:4414-4422.

Kishida S, Yamamoto H, Ikeda S, Kishida M, Sakamoto I, Koyama S \& Kikuchi A. (1998). Axin, a negative regulator of the wnt signaling pathway, directly interacts with adenomatous polyposis coli and regulates the stabilization of beta-catenin. J Biol Chem 273:10823-10826.

Lakowicz JR. (2006). Plasmonics in Biology and Plasmon-Controlled Fluorescence. Plasmonics 1:5-33

Lee YN, Gao Y, Wang HY. 2008. Differential mediation of the Wnt canonical pathway by mammalian Dishevelleds-1, -2, and -3. Cell Signal 20:443-452.

Lee YN, Malbon CC \& Wang HY. (2004). G alpha 13 signals via p115RhoGEF cascades regulating JNK1 and primitive endoderm formation. J Biol Chem 279:54896-54904.

Lijam N, Paylor R, McDonald MP, Crawley JN, Deng CX, Herrup K, Stevens KE, Maccaferri G, McBain CJ, Sussman DJ \& Wynshaw-Boris A. (1997). Social interaction and sensorimotor gating abnormalities in mice lacking Dol1. Cell 90:895-905.

Lilien J \& Balsamo J. (2005). The regulation of cadherin-mediated adhesion by tyrosine phosphorylation/dephosphorylation of beta-catenin. Curr Opin Cell Biol 17:459-465.

Liu T, DeCostanzo AJ, Liu X, Wang H, Hallagan S, Moon RT \& Malbon CC. (2001). G protein signaling from activated rat frizzled-1 to the beta-catenin-Lef-Tcf pathway. Science 292:1718-1722.

Liu T, Liu X, Wang H, Moon RT \& Malbon CC. (1999). Activation of rat frizzled-1 promotes Wht signaling and differentiation of mouse F9 teratocarcinoma cells via pathways that require Galpha(q) and Galpha(o) function. J Biol Chem 274:33539-33544.

Lu W, Yamamoto V, Ortega B \& Baltimore D. (2004). Mammalian Ryk is a Wht coreceptor required for stimulation of neurite outgrowth. Cell 119:97-108.

Mak BC, Kenerson HL, Aicher LD, Barnes EA \& Yeung RS. (2005). Aberrant beta-catenin signaling in tuberous sclerosis. Am J Pathol 167:107-116.

Malbon CC. (2005). G proteins in development. Nat Rev Mol Cell Biol 6:689-701.

McKay RM, Peters JM \& Graff JM. (2001). The casein kinase I family in Wnt signaling. Dev Biol 235:388-396.

Mikels A, Minami Y \& Nusse R. (2009). Ror2 receptor requires tyrosine kinase activity to mediate Wnt5A signaling. J Biol Chem 284:30167-30176

Mikels AJ \& Nusse R. (2006). Purified Wnt5a protein activates or inhibits beta-catenin-TCF signaling depending on receptor context. PLoS Biol 4:e115.

Miller WT. (2003). Determinants of substrate recognition in nonreceptor tyrosine kinases. Acc Chem Res 36:393-400. 
Nesvizhskii AI, Keller A, Kolker E \& Aebersold R. (2003). A statistical model for identifying proteins by tandem mass spectrometry. Anal Chem 75:4646-4658.

Nusse R. (2001). Developmental biology. Making head or tail of Dickkopf. Nature 411:255-256.

Nusse R. (2005). Wnt signaling in disease and in development. Cell Res 15:28-32.

Offermanns S, Mancino V, Revel JP \& Simon MI. (1997). Vascular system defects and impaired cell chemokinesis as a result of Galpha13 deficiency. Science 275:533-536.

Oishi I, Suzuki H, Onishi N, Takada R, Kani S, Ohkawara B, Koshida I, Suzuki K, Yamada G, Schwabe GC, Mundlos S, Shibuya H, Takada S \& Minami Y. (2003). The receptor tyrosine kinase Ror2 is involved in non-canonical Wnt5a/JNK signalling pathway. Genes Cells 8:645-654.

Pan W, Choi SC, Wang H, Qin Y, Volpicelli-Daley L, Swan L, Lucast L, Khoo C, Zhang X, Li L, Abrams CS, Sokol SY \& Wu D. (2008). Wnt3a-mediated formation of phosphatidylinositol 4,5-bisphosphate regulates LRP6 phosphorylation. Science 321:13501353.

Penton A, Wodarz A \& Nusse R. (2002). A mutational analysis of dishevelled in Drosophila defines novel domains in the dishevelled protein as well as novel suppressing alleles of axin. Genetics 161:747-762.

Piedra J, Martinez D, Castano J, Miravet S, Dunach M \& de Herreros AG. (2001). Regulation of beta-catenin structure and activity by tyrosine phosphorylation. J Biol Chem 276:2043620443.

Porter M, Schindler T, Kuriyan J \& Miller WT. (2000). Reciprocal regulation of Hck activity by phosphorylation of Tyr(527) and Tyr(416). Effect of introducing a high affinity intramolecular SH2 ligand. J Biol Chem 275:2721-2726.

Rapp UR, Gotz R \& Albert S. (2006). BuCy RAFs drive cells into MEK addiction. Cancer Cell 9:9-12.

Rothbacher U, Laurent MN, Deardorff MA, Klein PS, Cho KW \& Fraser SE. (2000). Dishevelled phosphorylation, subcellular localization and multimerization regulate its role in early embryogenesis. Embo J 19:1010-1022.

Roura S, Miravet S, Piedra J, Garcia de Herreros A \& Dunach M. (1999). Regulation of Ecadherin/Catenin association by tyrosine phosphorylation. J Biol Chem 274:3673436740

Schwarz-Romond T, Fiedler M, Shibata N, Butler PJ, Kikuchi A, Higuchi Y \& Bienz M. (2007a). The DIX domain of Dishevelled confers Wnt signaling by dynamic polymerization. Nat Struct Mol Biol 14:484-492.

Schwarz-Romond T, Merrifield C, Nichols BJ \& Bienz M. (2005). The Wnt signalling effector Dishevelled forms dynamic protein assemblies rather than stable associations with cytoplasmic vesicles. J Cell Sci 118:5269-5277.

Schwarz-Romond T, Metcalfe C \& Bienz M. (2007b). Dynamic recruitment of axin by Dishevelled protein assemblies. J Cell Sci 120:2402-2412.

Schwille P, Haupts U, Maiti S \& Webb WW. (1999). Molecular dynamics in living cells observed by fluorescence correlation spectroscopy with one- and two-photon excitation. Biophys J 77:2251-2265.

Seto ES \& Bellen HJ. (2006). Internalization is required for proper Wingless signaling in Drosophila melanogaster. J Cell Biol 173:95-106. 
Sicheri F, Moarefi I \& Kuriyan J. (1997). Crystal structure of the Src family tyrosine kinase Hck. Nature 385:602-609.

Stambolic V, Ruel L \& Woodgett JR. (1996). Lithium inhibits glycogen synthase kinase-3 activity and mimics wingless signalling in intact cells. Curr Biol 6:1664-1668.

Strovel ET, Wu D\& Sussman DJ. (2000). Protein phosphatase 2Calpha dephosphorylates axin and activates LEF-1-dependent transcription. J Biol Chem 275:2399-2403.

Sun TQ, Lu B, Feng JJ, Reinhard C, Jan YN, Fantl WJ \& Williams LT. (2001). PAR-1 is a Dishevelled-associated kinase and a positive regulator of Wnt signalling. Nat Cell Biol 3:628-636.

Swallow CJ, Ko MA, Siddiqui NU, Hudson JW \& Dennis JW. (2005). Sak/Plk4 and mitotic fidelity. Oncogene 24:306-312.

Tamai K, Zeng X, Liu C, Zhang X, Harada Y, Chang Z \& He X. (2004). A mechanism for Wnt coreceptor activation. Mol Cell 13:149-156.

Tolwinski NS, Wehrli M, Rives A, Erdeniz N, DiNardo S \& Wieschaus E. (2003). Wg/Wnt signal can be transmitted through arrow/LRP5,6 and Axin independently of Zw3/Gsk3beta activity. Dev Cell 4:407-418.

van Amerongen R \& Nusse R. (2009). Towards an integrated view of Wht signaling in development. Development 136:3205-3214.

Wallingford JB \& Habas R. (2005). The developmental biology of Dishevelled: an enigmatic protein governing cell fate and cell polarity. Development 132:4421-4436.

Wang J \& Wynshaw-Boris A. (2004). The canonical Wnt pathway in early mammalian embryogenesis and stem cell maintenance/differentiation. Curr Opin Genet Dev 14:533539.

Wellbrock C, Karasarides M \& Marais R. (2004). The RAF proteins take centre stage. Nat Rev Mol Cell Biol 5:875-885.

Wettschureck N, Moers A \& Offermanns S. (2004). Mouse models to study G-protein-mediated signaling. Pharmacol Ther 101:75-89.

Wharton KA, Jr. (2003). Runnin' with the Dvl: proteins that associate with Dsh/Dvl and their significance to Wnt signal transduction. Dev Biol 253:1-17.

Willert K, Brink M, Wodarz A, Varmus H \& Nusse R. (1997). Casein kinase 2 associates with and phosphorylates dishevelled. Embo J 16:3089-3096.

Willert K, Brown JD, Danenberg E, Duncan AW, Weissman IL, Reya T, Yates JR, $3^{\text {rd }}$ \& Nusse R. (2003). Wht proteins are lipid-modified and can act as stem cell growth factors. Nature 423:448-452.

Williams JC, Weijland A, Gonfloni S, Thompson A, Courtneidge SA, Superti-Furga G \& Wierenga RK. (1997). The 2.35 A crystal structure of the inactivated form of chicken Src: a dynamic molecule with multiple regulatory interactions. J Mol Biol 274:757-775.

Witte F, Bernatik O, Kirchner K, Masek J, Mahl A, Krejci P, Mundlos S, Schambony A, Bryja V \& Stricker S. (2010). Negative regulation of Wnt signaling mediated by CK1phosphorylated Dishevelled via Ror2. Faseb J 24:2417-2426.

Wong HC, Bourdelas A, Krauss A, Lee HJ, Shao Y, Wu D, Mlodzik M, Shi DL \& Zheng J.( 2003). Direct binding of the PDZ domain of Dishevelled to a conserved internal sequence in the C-terminal region of Frizzled. Mol Cell 12:1251-1260.

$\mathrm{Xu} \mathrm{W,} \mathrm{Harrison} \mathrm{SC \&} \mathrm{Eck} \mathrm{MJ.} \mathrm{(1997).} \mathrm{Three-dimensional} \mathrm{structure} \mathrm{of} \mathrm{the} \mathrm{tyrosine} \mathrm{kinase} \mathrm{c-Src.}$ Nature 385:595-602. 
Yanagawa S, van Leeuwen F, Wodarz A, Klingensmith J\& Nusse R. (1995). The dishevelled protein is modified by wingless signaling in Drosophila. Genes Dev 9:1087-1097.

Yokoyama N, Golebiewska U, Wang HY \& Malbon CC. (2010). Wnt-dependent assembly of supermolecular Dishevelled-3-based complexes. J Cell Sci 123:3693-3702.

Yokoyama N \& Malbon CC. (2007). Phosphoprotein phosphatase-2A docks to Dishevelled and counterregulates Wnt3a/beta-catenin signaling. J Mol Signal 2:12.

Yokoyama N \& Malbon CC. (2009). Dishevelled-2 docks and activates Src in a Wnt-dependent manner. J Cell Sci 122:4439-4451.

Zeng X, Tamai K, Doble B, Li S, Huang H, Habas R, Okamura H, Woodgett J \& He X. (2005). A dual-kinase mechanism for Wht co-receptor phosphorylation and activation. Nature 438:873-877. 


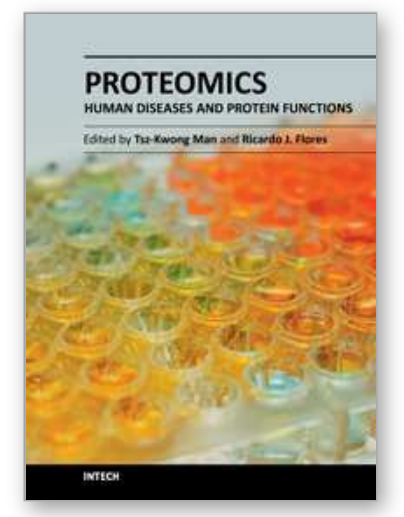

\author{
Proteomics - Human Diseases and Protein Functions \\ Edited by Prof. Tsz Kwong Man
}

ISBN 978-953-307-832-8

Hard cover, 438 pages

Publisher InTech

Published online 10, February, 2012

Published in print edition February, 2012

Biomedical research has entered a new era of characterizing a disease or a protein on a global scale. In the post-genomic era, Proteomics now plays an increasingly important role in dissecting molecular functions of proteins and discovering biomarkers in human diseases. Mass spectrometry, two-dimensional gel electrophoresis, and high-density antibody and protein arrays are some of the most commonly used methods in the Proteomics field. This book covers four important and diverse areas of current proteomic research: Proteomic Discovery of Disease Biomarkers, Proteomic Analysis of Protein Functions, Proteomic Approaches to Dissecting Disease Processes, and Organelles and Secretome Proteomics. We believe that clinicians, students and laboratory researchers who are interested in Proteomics and its applications in the biomedical field will find this book useful and enlightening. The use of proteomic methods in studying proteins in various human diseases has become an essential part of biomedical research.

\title{
How to reference
}

In order to correctly reference this scholarly work, feel free to copy and paste the following:

Noriko Yokoyama (2012). Proteomic Analysis of Wnt-Dependent Dishevelled-Based Supermolecular Complexes, Proteomics - Human Diseases and Protein Functions, Prof. Tsz Kwong Man (Ed.), ISBN: 978-953307-832-8, InTech, Available from: http://www.intechopen.com/books/proteomics-human-diseases-andprotein-functions/proteomic-analysis-of-wnt-dependent-dishevelled-based-supermolecular-complexes

\section{INTECH}

open science | open minds

\section{InTech Europe}

University Campus STeP Ri

Slavka Krautzeka 83/A

51000 Rijeka, Croatia

Phone: +385 (51) 770447

Fax: +385 (51) 686166

www.intechopen.com

\section{InTech China}

Unit 405, Office Block, Hotel Equatorial Shanghai

No.65, Yan An Road (West), Shanghai, 200040, China

中国上海市延安西路65号上海国际贵都大饭店办公楼 405 单元

Phone: +86-21-62489820

Fax: $+86-21-62489821$ 
(C) 2012 The Author(s). Licensee IntechOpen. This is an open access article distributed under the terms of the Creative Commons Attribution 3.0 License, which permits unrestricted use, distribution, and reproduction in any medium, provided the original work is properly cited. 